ANUARIo De Estudios Medievales

50/2, julio-diciembre de 2020, pp. 733-768

ISSN 0066-5061

https://doi.org/10.3989/aem.2020.50.2.04

\title{
LAS ABREVIATURAS POR LETRA SOBREPUESTA: SU LLEGADA Y USO EN DOCUMENTOS Y CÓDICES DE LEÓN Y CASTILLA*
}

\author{
ABBREVIATION BY SUPRASCRIPT LETTER: \\ ITS ARRIVAL AND USE IN CHARTERS AND BOOKS \\ FROM LEON AND CASTILE
}

\author{
FRANCISCO JAVIER MOLINA DE LA TORRE \\ Universidad de Valladolid \\ https://orcid.org/0000-0002-7923-3194
}

\begin{abstract}
Resumen: Las abreviaturas por letra sobrepuesta son un indicio de la influencia carolina en los testimonios manuscritos en escritura visigótica. Su lenta y desigual introducción en León y Castilla a lo largo de los siglos XI y XII ha suscitado preguntas en torno al papel de los escribas en el proceso. Este trabajo analiza documentos de entre 1050 y 1120 así como algunos códices, detallando cómo los distintos centros emplearon dicho recurso abreviativo a fin de estudiar la manera en que los escribas las adoptaron de distintas maneras y a distintos ritmos y las razones de su triunfo final.
\end{abstract}

Palabras clave: abreviatura por letra sobrepuesta; escritura visigótica; escritura carolina.

Abstract: Abbreviation by suprascript letter is a marker of Caroline minuscule influence in Visigothic script manuscript evidence. Its slow and uneven introduction in Leon and Castile during the $11^{\text {th }}$ and $12^{\text {th }}$ centuries has prompted questions regarding the role of the scribes in this process. The present article analyses documents between 1050 and 1120 as well as some books, providing detailed information on the use of abbreviations by suprascript letter in different scriptoria during this period in order to explore how scribes adopted them and the reasons behind their eventual triumph.

Keywords: abbreviation by suprascript letter; Visigothic script; Caroline minuscule.

\section{SUMARIO}

1. Introducción.- 2. El recurso a la letra sobrepuesta a la hora de abreviar.- 3. Las abreviaturas por letra sobrepuesta en León y Castilla.- 3.1. Un repaso a las abreviaturas por letra sobrepuesta en documentos.- 3.2. Un repaso a las abreviaturas por letra sobrepuesta en códices.- 4. El largo proceso de adopción de la abreviatura carolina por letra sobrepuesta.- 4.1. ¿Cómo adoptaron los escribas visigóticos las abreviaturas por letra sobrepuesta?- 4.2. ¿Por qué adoptaron los escribas visigóticos las abreviaturas por letra sobrepuesta?- 5. Conclusiones.- 6. Tablas.7. Láminas.- 8. Bibliografía citada.

\footnotetext{
${ }^{*}$ Este trabajo es parte del Proyecto de Investigación "Poder, Sociedad y Fiscalidad al norte de la corona de Castilla en el tránsito del medievo a la modernidad", financiado por el Ministerio de Economía y Competitividad (HAR201452469-C3-3-P). Una versión inicial del mismo fue presentada en inglés en el 2016 International Medieval Congress in Leeds (Sessions: The Reception and Evolution of Caroline Minuscule in the Iberian Peninsula). Quiero agradecer a todos los participantes sus comentarios y sugerencias y en particular a Ainoa Castro Correa por su invitación a participar en él.

Citation / Cómo citar este artículo: Molina de la Torre, Francisco Javier (2020), Las abreviaturas por letra sobrepuesta: su llegada y uso en documentos y códices de León y Castilla, "Anuario de Estudios Medievales" 50/2, pp. 733-768. https:// doi.org/10.3989/aem.2020.50.2.04

Copyright: (C) 2020 CSIC. Este es un artículo de acceso abierto distribuido bajo los términos de la licencia de uso y distribución Creative Commons Reconocimiento 4.0 Internacional (CC BY 4.0).
} 


\section{INTRODUCCIÓN ${ }^{1}$}

¿Cómo percibieron los escribas el cambio gráfico de la escritura visigótica a la carolina? No hay fácil respuesta a este interrogante planteado por Ainoa Castro Correa en el XIX Coloquio del Comité internacional de paleografía latina ${ }^{2}$. Todo cambio gráfico es un proceso complejo en el que no solo se transforma la estructura de la letra; junto a ello, hay una serie de aspectos como el uso de las abreviaturas o la reorganización del espacio de escritura que también han de tenerse en cuenta $^{3}$. En este sentido, en la transición de la escritura visigótica a la carolina se ha advertido que el sistema abreviativo carolino penetró de forma temprana en el sistema gráfico visigótico, de modo que nos encontramos ante una situación híbrida en la que con frecuencia se entremezclan elementos del sistema abreviativo visigótico con otros ya procedentes del carolino (lám. 1) ${ }^{4}$. Uno de los recursos carolinos que adoptaron los escribas visigóticos a la hora de abreviar fue la letra sobrepuesta, una forma singular en la que el signo abreviativo que acompaña a la parte alfabética de la abreviatura es también parte alfabética de la misma ${ }^{5}$.

En este capítulo pretendemos analizar el uso que los escribas que empleaban la letra visigótica hicieron de este recurso abreviativo en los reinos de León y Castilla a finales del siglo XI y comienzos del siglo XII. El repaso de los testimonios gráficos, tanto documentales como librarios, que hemos llevado a cabo nos permitirá ofrecer algunos matices en cuanto al momento de su introducción, al mismo tiempo que nos llevará a plantearnos cómo y

${ }^{1}$ Abreviaturas usadas: $\mathrm{ACB}=$ Burgos, Archivo de la Catedral; $\mathrm{ACC}=$ Calahorra, Archivo de la Catedral; ACL = León, Archivo de la Catedral; ACV = Valladolid, Archivo de la Catedral; AHDL = León, Archivo Histórico Diocesano; AHN = Madrid, Archivo Histórico Nacional; ANTT $=$ Lisboa, Arquivo Nacional da Torre do Tombo; ARCV = Valladolid, Archivo de la Real Chancillería; BAV = Ciudad del Vaticano, Biblioteca Apostólica Vaticana; BL = Londres, British Library; $\mathrm{BN}=$ Madrid, Biblioteca Nacional; $\mathrm{BNF}=$ Paris, Bibliothèque Nationale de France; CEISI = Centro de Estudios e Investigación "San Isidoro"; CLA = Codices Latini Antiquiores; ChLA = Chartae Latinae Antiquiores; CSang: Codex Sangallensis (St. Gallen, Stitfsbibliothek); RAH = Madrid, Real Academia de la História; RBME = El Escorial, Real Biblioteca del Monasterio de San Lorenzo.

${ }^{2}$ Castro Correa 2019, p. 26.

${ }^{3}$ De Robertis, Giovè 2019, p. 14.

${ }^{4}$ Según Giovè Marchioli (1993, p. 13), un sistema abreviativo exige un método unitario y organizado. En este sentido, existen en el periodo que estudiamos dos sistemas abreviativos con sus propios recursos y signos -el visigótico y el carolino-, y algunos recursos gráficos del sistema carolino aparecen en textos visigóticos. En la Lám. 1 encontramos un pequeño fragmento del Beato de Silos (BL,Add. Mss. 11695, f. 90r) en el que el -us final de aspicimus en la primera línea aparece abreviado conforme a las convenciones visigóticas, en tanto que el - $u s$ final de inuenimus y actibus en la segunda línea lo hace al modo carolino.

${ }^{5}$ Cencetti 1954, pp. 395, 441-446. 
por qué se introdujo la abreviatura por letra sobrepuesta incluso antes que la propia escritura carolina.

\section{EL RECURSO A LA LETRA SOBREPUESTA A LA HORA DE ABREVIAR}

Las abreviaturas, aunque tal vez no hayan gozado de la atención que merecen $^{6}$, han sido objeto de interés a lo largo de la historia ${ }^{7}$. Entre ellas, el recurso a la letra sobrepuesta se ha empleado desde la época clásica, tal como muestran los estudios de Bell y, sobre todo, de Blanchard, centrados en su uso en los papiros documentarios griegos ${ }^{8}$. En el mundo latino los ejemplos más antiguos de letra sobrepuesta se remontan a la segunda mitad del siglo II y al siglo III, y se plantea su catalogación como sigla o como abreviatura por suspensión ${ }^{9}$. En cualquier caso, lo que permite entrever ese primer uso de la letra sobrepuesta es la inexistencia de un sistema definido, pues una misma grafía (por ejemplo, $m^{\circ}$ ) servía para abreviar palabras diversas (modii, mortis).

En el paso del mundo romano al periodo medieval, los primeros estudios insistieron en el protagonismo de los escribas irlandeses. La meticulosa labor de Lindsay ha mostrado cómo la letra sobrepuesta pervivió en el mundo insular -el libro de Dimma o el Bonifatianus 3 de Fulda son buenos ejemplos de ello ${ }^{10}$, siendo después exportada a monasterios como Bobbio o St. Gall. Sin embargo, el uso de la abreviatura por letra sobrepuesta en los scriptoria del continente se redujo enormemente a comienzos del periodo carolingio, algo que, según Edward Rand: may have sprung not from ignorance but from principle $^{11}$.

\footnotetext{
${ }^{6}$ Giovè Marchioli 2016, p. 42.

${ }^{7}$ Aunque hubo compendios en época medieval (RBME, T-II-24) y moderna, como las Abreviaturas de Vázquez del Mármol (cf. Olmedilla Herrero 1993), es solo a partir del siglo XIX cuando el interés por la abreviatura se generaliza: Chassant 1876; Traube 1907; Cappelli 1912; Lindsay 1915; Schiaparelli 1926. Más recientemente, sobre todo en el ámbito italiano, se ha renovado el planteamiento del tema con nuevas inquietudes (Caligiani 1993; De Robertis 1993; Giovè Marchioli 1991, 1993, 2016), lo que ha llevado a consideraciones al respecto también en nuestro país (Ruiz García 1994-1995; Sánchez Prieto 2001). Finalmente, el desarrollo de las humanidades digitales ha obligado a plantear la cuestión desde un ángulo diferente: Parkinson, Emiliano 2002; Honkapohja 2013.

${ }^{8}$ Bell 1953; Blanchard 1974. Por su parte, McNamee 1981, que ofrece un minucioso listado alfabético de abreviaturas en los papiros literarios y en los ostraca, señala que "in abbreviations by suprascript letter the suprascript is usually the last letter retained in the word. Ordinarily it is written above or above and to the right of the letter that precedes it" (p. XII). Schiaparelli 1926, p. 61, al analizar el uso de la letra sobrepuesta en latín, ha subrayado su origen griego y su conexión con las notae iuris .

${ }^{9}$ Giovè Marchioli 1993, pp. 61, 75, 92, 96.

${ }^{10}$ Lindsay 1915.

${ }^{11}$ Rand 1927, p. 175.
} 
El análisis que hizo Lindsay de los códices de Bobbio ${ }^{12}$ mostró cómo, tras una fase inicial en torno al 700, donde el influjo irlandés es muy acentuado y existen numerosos ejemplos de abreviaturas por letra sobrepuesta, un segundo momento condujo al abandono de muchas de ellas. Así, en numerosos códices de los siglos VIII y IX solo hay casos de qui, pri, pra y uero. Schiaparelli llegó a parecidas conclusiones, sosteniendo que algunos manuscritos recurren a abreviaturas irlandesas en menor proporción o incluso solo de forma excepcional ${ }^{13}$. El minucioso estudio de Collura sobre el scriptorium de Bobbio incluye algunos códices del siglo X; en ellos el número de abreviaturas por letra sobrepuesta tiende a ir en aumento, si bien se limita a unas pocas combinaciones (uero, ergo, mihi, nihil, supra, y las sílabas qui, pra y qua) ${ }^{14}$.

Franz Steffens estudió la presencia de este tipo de abreviaturas en St. Gall ${ }^{15}$. No hay ejemplos de este recurso en los códices del siglo VIII que analizó y solo qui y pri sobrepuestos en códices del siglo IX. Sin embargo, aunque la revisión que hemos hecho de una serie de códices compuestos en el monasterio durante los siglos IX y X tiende a confirmar las observaciones de Steffens ${ }^{16}$, es preciso atender a las particularidades del contexto ${ }^{17}$. Por ejemplo, CSang 555 presenta este recurso para abreviar pra y qui; no obstante, lo cierto es que hay siete casos de pra (y algunos parecen haber sido corregidos) y un caso de qui (y la palabra aqiloneum fue añadida entre renglones). De forma parecida, es verdad que en CSang 180 aparece la sílaba qui abreviada por letra sobrepuesta, pero los únicos dos casos (p. 239) parecen proceder de otro manuscrito.

\section{LAS ABREVIATURAS POR LETRA SOBREPUESTA EN LEÓN Y CASTILLA}

Las abreviaturas por letra sobrepuesta han sido una especie de "fósil guía" en el estudio de la introducción de la minúscula carolina en León y Castilla. Estudios previos de Ostolaza Elizondo, Ruiz Asencio, Calleja Puerta y

\footnotetext{
${ }^{12}$ Lindsay 1909.

${ }^{13}$ Schiaparelli 1926, p. 122.

${ }^{14}$ Collura 1943, pp. 144-157, 170-174.

${ }^{15}$ Steffens 1913.

${ }^{16}$ Gracias a la magnífica página web de las bibliotecas y archivos suizos (http://www. e-codices.unifr.ch), ha sido posible estudiar página a página varios Codices Sangallenses: 216 (fechado ca. 800; no hay abreviaturas por letra sobrepuesta), 180 (datado en el primer tercio del siglo IX; aparece qui abreviado por letra sobrepuesta), 555 (datado en el tercer cuarto del siglo IX; pra y qui abreviados por letra sobrepuesta), 559 (fechado $c a .900$; no presenta este tipo de abreviaturas), 284 (datado en torno al 920-925; qua, qui y quo se hallan abreviados por letra sobrepuesta), y 677 (fechado en el siglo X; no contiene abreviaturas por letra sobrepuesta).

${ }^{17} \mathrm{Al}$ respecto, cf. Bozzolo, et al. 1990, pp. 20-21; Giovè Marchioli 1991, pp. 17-20.
} 
Serna Serna entre otros han recurrido a ellas como indicio de la llegada de la escritura carolina a la región ${ }^{18}$.

Siguiendo sus huellas y en deuda con ellos, esperamos dar un paso más en dos sentidos. Por un lado, la muestra que analizaremos es más amplia. Hemos considerado documentos fechados en este periodo ( $c a$. 1050-1120) de un mayor número de catedrales y monasterios y, además, hemos incluido varios testimonios librarios en el repaso. Por otro lado, aunque podamos advertir la existencia de signos abreviativos de origen carolino, nuestra atención se ha centrado en el uso de la letra sobrepuesta. ¿Cuáles son, de hecho, estas abreviaturas? ¿Existe alguna pauta en su empleo?

\subsection{Un repaso a las abreviaturas por letra sobrepuesta en docu-} mentos

El repaso siguiente recoge información de los diplomas conservados en diversas catedrales y monasterios de los territorios de León y Castilla entre 1050 y 1120: León, Palencia, Burgos, Lugo, Salamanca, Zamora, Segovia, Calahorra, Valladolid, Sahagún, Eslonza, Otero de las Dueñas y Oña ${ }^{19}$. La mayoría están escritos en visigótica, aunque aparecen algunos ya en minúscula carolina desde la última década del siglo XI. En total, tras revisar más de 500 documentos, hemos hallado 780 casos de abreviatura por letra sobrepuesta.

El Archivo de la Catedral de León ${ }^{20}$ guarda 126 documentos fechados entre 1050 y 1120, 106 en letra visigótica, 1 en una escritura híbrida (de transición) y 19 en minúscula carolina, si bien las abreviaturas por letra sobrepuesta aparecen solo en 22 diplomas en visigótica y 11 en carolina. El texto más temprano (ACL 262), fechado en 1078, presenta dos casos de $t^{i}$-tibi-, uno de modo en quom $^{o}$ y uno de $q^{i}$ (lám. 2). Este sistema abreviativo se emplea solo en cuatro documentos de 1080 a 1089, en los que se abrevian un total de 12 palabras (un ejemplo de tibi, ocho de qui y tres de pro) y en siete diplomas fechados entre 1090 y 1099, donde aparecen abreviadas por letra sobrepuesta 34 palabras (además de $q^{i}, m^{i}, t^{i}-t i b i-\mathrm{y} p^{o}$, hay cuatro casos de $p^{i}$-tres en el mismo documento-, uno de $p^{a}$ y otro de $q^{o}$ ). Tres documentos en letra visigótica presentan este sistema entre 1100 y 1109, cuando el dominio de $q^{i}$ es aún mayor (más del $58 \%$ de todos los casos). Finalmente, al periodo que va de 1110 a 1120 pertenecen otros seis diplomas escritos en letra visigó-

\footnotetext{
${ }_{18}$ Ostolaza Elizondo 1990; Ruiz Asencio 2008; Serna Serna 2008; Calleja Puerta 2011.

${ }^{19} \mathrm{Al}$ hablar de cada centro en particular remitimos a la bibliografía pertinente.

${ }^{20}$ Ruiz Asencio 1989; Fernández Catón 1990.
} 
tica. Aunque el número de palabras abreviado por letra sobrepuesta aumenta (36 palabras), las combinaciones silábicas se reducen a $q^{o}, p^{i}, p^{o}$ y, sobre todo, $q^{i}$ (superando el $60 \%$ de los casos). Por otro lado, un documento (ACL 972) es considerado una copia de un falso del rey Ordoño II y se ha fechado en la segunda mitad del siglo $\mathrm{XI}^{21}$. Sin embargo, el uso de este sistema abreviativo en palabras como antiq ${ }^{o} s, q^{a}$ drata, $q^{a}$ dragesima o $q^{o}$ cumque apunta más bien a la última década del siglo XI o a comienzos del siglo XII. Es solo con la introducción de la minúscula carolina cuando aumentan las posibilidades abreviativas. En los once documentos escritos en carolina entre 1107 y 1120 se emplea este sistema en 81 palabras, y, aunque $q^{i}$ persiste como la abreviatura más común, aparecen nuevas combinaciones: $t^{a}, t^{o}, g^{o}-$ ergo-,$n^{i}-n i s i-$, etc.

En la colección diplomática de Otero de las Dueñas ${ }^{22}$, el influjo de este recurso del sistema abreviativo carolino en los documentos en letra visigótica es tardío. El primer caso (AHDL, Otero, 207) se remonta a 1097 (donde encontramos letras sobrepuestas en cinco palabras que contienen la sílaba $q^{i}$ ), $\mathrm{y}$, de hecho, $q^{i}$ y $p^{o}$ serán básicamente las únicas abreviaturas hasta 1120, si bien hay casos de $m^{i}$-mihi - (AHDL, Otero, 221), $m^{o}$-modo- (AHDL, Otero, 217) y $p^{i}$ : Cipianiz (AHDL, Otero, 217-1). Como es de esperar, los documentos en escritura visigótica más tardíos, fechados ya a mediados del siglo XII (1147 y 1154), en un momento en el que la minúscula carolina había triunfado, ofrecen un número de abreviaturas por letra sobrepuesta mucho mayor: $q^{i}, p^{o}$, $t^{i}-t i b i-, q^{o}, t^{o}, m^{i}$ y $q^{a}$.

Hemos analizado 42 documentos fechados entre 1050 y 1120 pertenecientes al monasterio de San Pedro de Eslonza, de los cuales 40 están escritos en letra visigótica y 2 en minúscula carolina ${ }^{23}$. De los 40 diplomas visigóticos, encontramos abreviaturas por letra sobrepuesta en 19 de ellos. El primero, escrito por un escriba de nombre Claudius, se fecha en 1080 y presenta 9 palabras abreviadas mediante dicho sistema: $\sup ^{a}$ dicto, pasq $^{i} s, p^{i}$ mis, $p^{o} p^{i} a m, q^{i} d q^{i} d, p^{o}$ lis y tres casos de $p^{o}$. No hay más ejemplos de estas abreviaturas hasta la década de 1090, cuando encontramos 82 palabras abreviadas de ese modo en 10 documentos. Sin embargo, al considerarlas más detenidamente, se advierte que la sílaba $q^{i}$ equivale a más del $47 \%$, mientras que $p^{o}$ supone un $17 \%, p^{i}$, un $15,8 \%$ y $p^{a}$, un $12,1 \%$. Las restantes abreviaturas son mucho menos frecuentes: $q^{o}$ (4 casos), $q^{a}(2), m^{i}-m i h i-(2), t^{i}-t i b i-(1)$ y $n^{i}-n i s i-(1)$; más aún, es un único escriba (Martinus) quien empleó $m^{i}, t^{i}$ y $n^{i}$ en los dos do-

${ }^{21}$ Sáez 1987, p. 108.

${ }^{22}$ Fernández Flórez, Herrero de la Fuente 1999, 2005.

${ }^{23}$ Ruiz Asencio, Ruiz Albi 2007. 
cumentos que redactó (AHN, Clero, carp. 960, docs. 18 y 20) ${ }^{24}$. El número de documentos en escritura visigótica con abreviaturas por letra sobrepuesta de comienzos del siglo XII (1100-1110) es reducido (6) y refleja la consolidación de abreviaturas como $m^{i}$ y $m^{o}-$ modo-

Particular atención merece el monasterio de Sahagún, pues su colección nos brinda 271 documentos aprovechables desde 1050 hasta 1120, si bien hay enormes diferencias entre unas décadas y otras. En su edición de los documentos $^{25}$, Herrero de la Fuente y Fernández Flórez indican que 120 de ellos presentan rasgos característicos del sistema abreviativo carolino, aunque tal cifra es discutible. En cualquier caso, solo 42 incluyen abreviaturas por letra sobrepuesta. Anteriormente, en un documento fechado en 1029, encontramos pro con la $o$ sobrepuesta $-p^{o}-$, pero no hay más documentos que presenten dicho sistema hasta 1062 (cuando aparece $q^{\circ}$ ). Esta tendencia cambia lentamente hacia la década de 1080 (10 casos: $\left.q^{i}[6], q^{a}[1], q^{o}[1], p^{o}[1], p^{i}[1]\right) \mathrm{y}$, sobre todo, a partir de 1090, cuando estas abreviaturas se hacen mucho más numerosas. De todos modos, el análisis detallado de los documentos muestra que el número de abreviaturas se reduce a un puñado de ellas (en particular, $q^{i}, p^{o}$ y $p^{i}$ ). De hecho, $q^{i}$ supone más del $50 \%, p^{o}$ equivale más o menos a un $18 \%$ y $p^{i}$ a un $10 \%$ aproximadamente. Más aún, muchas de las demás sílabas y palabras abreviadas de este modo $\left(p^{e}, q^{a}, t^{i}-t i b i-, t^{i}-t r i-\right)$ corresponden a un único diploma redactado en 1099 por un escriba anónimo. En lo tocante al siglo XII, hay 84 abreviaturas por letra sobrepuesta en los documentos escritos en visigótica: mientras que siguen predominando $q^{i}(29,7 \%)$ y $p^{o}(26,1 \%)$, avanza el uso de otras combinaciones silábicas como $p^{a}, t^{a}$ o $q^{a}$.

Los primeros documentos en minúscula carolina ofrecen un patrón similar: los cuatro documentos anteriores a 1110 (AHN 891/12, 13, 22; 892/1) contienen 34 abreviaturas de este tipo y más del $41 \%$ corresponden a la sílaba $q^{i}$. Parecida proporción (44\%) se halla en los diplomas carolinos entre 1110 y 1120; no obstante, existen algunas novedades significativas: el número de abreviaturas por letra sobrepuesta aumenta notablemente (hay 140 casos en 11 documentos) y desaparece la abreviatura de $p^{o}$ con la $o$ sobrepuesta, siendo sustituida por el signo continental de pro. Sin embargo, el uso de este sistema abreviativo entre los escribas que emplean la minúscula carolina también es muy irregular: mientras que en un único documento (AHN 893/22) Pelagius incluye casi 30 palabras abreviadas de este modo (con ejemplos de sílabas inusuales como $\mathrm{cra}-\mathrm{c}^{a}-$, tra $-t^{a}-\mathrm{o}$ sibi $-s^{i}$ ), el diácono Galindus (AHN 893/12) recurre a él solo en una ocasión ( propinq $^{i}$ s).

\footnotetext{
${ }^{24}$ A partir de ahora, remitiremos a los documentos de la sección Clero del Archivo Histórico Nacional de Madrid mencionando la carpeta y el documento (por ejemplo, AHN 960/18).

${ }^{25}$ Herrero de la Fuente 1988a, 1988b; Fernández Flórez 1991.
} 
En el caso de Lugo $^{26}$, hay siete diplomas en escritura visigótica fechados entre 1091 y 1119 , para un total de 18 palabras abreviadas por letra sobrepuesta. A diferencia de lo que hemos visto en otros lugares, aquí se da una distribución más uniforme de las abreviaturas: seis casos de $q^{i}$, cinco de $p^{o}$, dos de $p^{i}$ y $p^{a}$, y uno de $t^{i}-t i b i-, u^{o}$-uero-, y $n^{l}-$ nihil-.

El Archivo de la Catedral de Palencia ${ }^{27}$ nos brinda ocho documentos en escritura visigótica datados entre mediados del siglo XI y comienzos del siglo XII. En ellos son poco frecuentes las abreviaturas por letra sobrepuesta: solo un documento (arm. III, leg. 1, doc. 9), fechado en 1090, incluye cinco palabras diferentes, aunque en todas ellas lo que se abrevia es la sílaba $q^{i}$.

Respecto a Valladolid, el Archivo Catedralicio custodia 15 documentos pertinentes para nuestros fines: 4 escritos en letra visigótica, 9 en minúscula carolina y 2 en una escritura híbrida. Sin embargo, solo 8 presentan abreviaturas por letra sobrepuesta (para un total de 50 casos). El único diploma en escritura visigótica (ACV 10/56), fechado en 1101, contiene dos palabras $\left(q^{a} n t a\right.$ y $\left.p^{o}\right)$. Curiosamente, hay documentos carolinos anteriores, puesto que ACV 25/1 es considerado un original de $1092^{28}$. Este documento presenta un amplio abanico de abreviaturas por letra sobrepuesta, con sílabas como $t^{i}$ $-t r i-, q^{i}, p^{i}$ y palabras como $q^{o} m^{o}$ y $m^{i}$. Como suele ser habitual, la sílaba $q u i$ supone la mitad de todas las abreviaturas de este tipo, en tanto que pro con $o$ sobrepuesta solo aparece en una ocasión.

El Archivo de la Catedral de Burgos posee un total de 13 documentos en letra visigótica fechados entre 1068 y $1120^{29}$. Sin embargo, el influjo carolino puede detectarse solo en 5 de ellos y únicamente 3 presentan abreviaturas por letra sobrepuesta (ACB, vol. 34, ff. 44, 347; vol. 35, f. 745). El primero, escrito en 1094, contiene dos casos de $u^{o}$ y uno de $p^{i}$ or. En un diploma de 1107 aumentó tanto el número como la diversidad de abreviaturas por letra sobrepuesta: $\operatorname{prop}^{i} a, q^{i}, u^{o}, m^{o}, \sup ^{a}$ sc $^{i}$ pto y sup $^{a}$. Algo parecido encontramos en el documento que redactó Ordonius en 1120, donde encontramos otros 7 ejemplos de este tipo de abreviatura: $m^{o}, m^{i}$, quisq $^{i} s$, Ruderiq ${ }^{i} z, \sup ^{a}$ scriptis, $p^{o}$ priis y sup ${ }^{a}$ dictus.

Según el último repaso de la documentación visigótica del monasterio de San Salvador de Oña ${ }^{30}$, hay 27 documentos originales. Sin embargo, solo 4 de ellos presentan abreviaturas por letra sobrepuesta (AHN 271/23;

\footnotetext{
${ }^{26}$ Castro Correa 2012.

${ }^{27}$ San Martín Payo 1983; Francia Lorenzo 1987.

${ }^{28}$ Ruiz Asencio 2008, p. 115.

${ }^{29}$ Serna Serna 2008, p. 205. Agradezco a la Dra. Sonia Serna Serna su amabilidad al permitirme acceder a las imágenes digitales que poseía de esos documentos.

${ }^{30}$ Vivancos 2012.
} 
$272 / 4,8,13)$. El primero se remonta a 1099 e incluye un caso de $m^{i}-m i h i-$ y otro de $n^{i}$-nisi-. Por otro lado, la gran diversidad de abreviaturas en el texto de la donación de Mayor y Anderquina al monasterio escrito en 1102 revela un escriba (al que por desgracia desconocemos) completamente familiarizado con el sistema: $q^{i}, q^{a} m, q^{a}$ ntum, $q^{i}$ ntana $, a l i q^{a}, q^{i} s, \sup ^{a}, p^{i} n c i p i, t^{i}(t i b i)$ y $P e t^{a-}$ pidonia. Los dos documentos restantes (fechados en 1107 y 1111) brindan tan solo tres casos de $q^{i}$ y uno de $s c^{i} p s i t$.

Por último, el Archivo de la Catedral de Calahorra guarda siete documentos pertinentes desde 1050 hasta $1120^{31}$. Sin embargo, no hay diplomas en escritura visigótica que empleen este sistema abreviativo. Los únicos dos ejemplos datan ya de 1132 (ACC, s. ${ }^{\text {a }} 24$ A) y 1136 (ACC, s. ${ }^{\text {a } 29), ~ y, ~ c o m o ~}$ es de esperar en una fecha tan tardía, ambos muestran un amplio abanico de abreviaturas: $m^{i}, q^{i}$, sup $p^{a}$ dicta,$X^{o}$ (Christo), Pet ${ }^{o}$, sc $^{i}$ ptor, $q^{i}$ dem, $q^{e}, q^{a}$ ntum, $q^{i}$ etum, $q^{o} q u e, u^{o}$.

¿Qué podemos deducir de este repaso de los documentos? En primer lugar, aunque hay algunos ejemplos anteriores, la verdadera introducción de las abreviaturas por letra sobrepuesta en los territorios de León y Castilla debe situarse en la última década del siglo XI. Tal como puede observarse en la tabla 1, en las décadas previas a 1080 solo hay 20 casos en total, y 31 más entre 1081 y 1090. En este sentido, el uso de letras sobrepuestas como abreviaturas es un influjo carolino que aparece en los documentos más tarde que, por ejemplo, el signo de -us final, la abreviatura de per con un trazo cruzando el caído de la $p$ o la abreviatura de pro en forma de bucle a la izquierda. Más aún, antes de 1090 solo hay ejemplos en Sahagún, León y Eslonza (los cinco casos de Palencia datan de ese año).

Esto nos lleva a una segunda observación: la llegada de este sistema abreviativo revela notables diferencias entre los distintos centros escriptorios. En tanto que Sahagún, León, Eslonza e incluso Valladolid se muestran prestos a la hora de adoptarlo, tanto en la escritura visigótica como en la carolina, en otros territorios será aceptado lentamente. Además, no solo los diversos scriptoria presentan diferencias llamativas entre ellos, también la situación en un mismo scriptorium es sumamente diversa: mientras que algunos escribas adoptaron rápidamente e hicieron abundante uso de esta forma de abreviar, otros monjes en el mismo centro apenas la utilizaron o ni siquiera lo hicieron. Así, los tres documentos de Sahagún escritos entre 1108 y 1122 por un Martinus vinculado al monasterio de Saelices de Mayorga (AHN 892/20; 893/7; 894/7) no presentan ninguna abreviatura por letra sobrepuesta, si bien manifiestan otros influjos carolinos. Por el contrario, otro Martinus domina por

${ }^{31}$ Rodríguez de Lama 1976. 
completo el sistema, empleándolo no solo para abreviar sílabas como $q^{i}$ y $p^{o}$; los cuatro documentos que le pueden ser atribuidos (AHN 892/11-12; 893/11 y 15) ofrecen ejemplos de palabras como $u^{o}$-uero- y $t^{i}$-tibi- y de sílabas como $p^{a}, t^{a}, q^{a}, q^{o}$ y $q^{i}$.

Por último, hemos de decir algo acerca de las palabras y las sílabas que se abrevian. Según muestra la tabla 2, ocho abreviaturas por letra sobrepuesta $\left(q^{i}, p^{o}, p^{i}, t^{i}-t i b i-, q^{a}, q^{o}, p^{a}\right.$ y $\left.m^{i}\right)$ equivalen aproximadamente al $90 \%$ del total. Además, destaca el dominio de $q^{i}$, que representa el $46 \%$. Cuando consideramos este tipo de abreviaturas en los documentos en escritura visigótica, el panorama resultante no varía demasiado, ya que $q^{i}, p^{o}$ y $p^{i}$ son, con mucho, las más usadas. De todos modos, nos gustaría llamar la atención sobre el uso de $p^{o}$. Mientras que, en los documentos visigóticos, supone un $20 \%$ del total de abreviaturas por letra sobrepuesta, en los diplomas escritos en minúscula carolina esa cifra cae al $12 \%$. De forma similar, la tabla 4 muestra cómo la abreviatura de pro va desapareciendo según avanza el siglo XII. Como es de esperar, ello se debe a la progresiva sustitución de pro con $o$ sobrepuesta $\left(p^{o}\right)$ por el signo carolino habitual. En la medida en que la escritura visigótica fue reemplazada por la carolina, hay menos riesgo de confundir la abreviatura visigótica de per con el pro carolino $^{32}$. Por último, la tabla 5 ofrece una visión década por década de todas las abreviaturas por letra sobrepuesta en los documentos que hemos estudiado de 1070 a 1120 .

\subsection{Un repaso a las abreviaturas por letra sobrepuesta en códices}

Pasamos a continuación a analizar algunos códices asignados al territorio y al periodo que estamos considerando ${ }^{33}$, una muestra que equivale aproximadamente a un tercio de los testimonios conocidos, aunque debido al carácter fragmentario de algunos textos y al reducido número de ejemplos en otros, las tablas finales (6-11) solo recogen cinco ejemplares que consideramos significativos.

\footnotetext{
${ }^{32}$ Sin embargo, hay diplomas visigóticos que combinan los signos de per visigótico y pro carolino. Aunque, en Europa, $p^{o}$ tiende a abreviar post (Lindsay 1915, pp. 190-195), puede emplearse, como veremos, como abreviatura de pro.

${ }^{33}$ El Corpus de Códices Visigóticos (Millares Carlo 1999) habla del uso de este recurso abreviativo en los números 16, 17, 27, 36, 93, 94, 99, 100, 101, 124, 125, 129, 137, 161, 228 , 233, 234, 286, 328. En el catálogo incluido en la página web Littera Visigothica encontramos 35 códices y fragmentos que podemos asignar a este periodo y territorio; el catálogo está disponible en http://www.litteravisigothica.com/articulo/catalogue-of-visigothic-script-manuscripts [consulta: 09/03/2020].
} 
Procedentes de la abadía de Santo Domingo de Silos hemos analizado el Beato, hoy en Londres ${ }^{34}$, y un Leccionario, hoy en París ${ }^{35}$. El primero no presenta ningún caso de abreviatura por letra sobrepuesta, aunque sí se advierte el influjo franco en el uso de la grafía típica del mundo carolino para la terminación - us (ff. 40v, 45r, 85r, 90r...). En el leccionario, por el contrario, se recurre con frecuencia a la letra sobrepuesta para abreviar ${ }^{36}$ : términos como uero y nisi se abrevian sistemáticamente como $u^{o}$ y $n^{i}$; más interesantes pueden ser las reflexiones en torno a la sílaba qui, pues el escriba conoce el signo visigótico y la abreviatura por letra sobrepuesta. No obstante, parece -con algunas excepciones $\left(l o q^{i}, q^{i} n q u e, q^{i} s\right.$, aliq $\left.^{i} \ldots\right)$, sobre todo donde las abreviaturas son más abundantes- que para el nominativo del pronombre relativo se emplea la letra sobrepuesta, mientras que en las demás combinaciones lo más frecuente es usar el signo visigótico.

El Poenitentiale de Buchardus ${ }^{37}$, copiado en 1105, refleja en buena medida lo que encontramos en los documentos (tabla 6). En este caso particular, qua puede hallarse sobrerrepresentado, porque a veces la penitencia impuesta consistía en estar a pan y agua, apareciendo escrito como pane et $a q^{a}$.

El Becerro de Sahagún o Liber testamentarum sancti Facundi es un cartulario escrito en el monasterio homónimo que incluye documentos del 904 al $1165^{38}$. Si bien la mayor parte del libro está escrito en una visigótica tardía (ff. 1r-237v), los últimos folios incluyen documentos en minúscula carolina (ff. 238r-242v) y un índice de época moderna (ff. 244r-248v) ${ }^{39}$. Tras comparar el Becerro con diplomas escritos por Munio Díaz, tradicionalmente se le ha atribuido a este escriba su redacción ${ }^{40}$. Respecto a la datación, a la luz de una nota en la última línea de la segunda columna del f. 141r (iste liber scriptus est in era millesima CXLVIII) y dado que el último diploma copiado en la sección en letra visigótica se data en 1110, tradicionalmente se le ha asignado esa fecha.

\footnotetext{
${ }^{34}$ BL, Add. Ms. 11695.

${ }^{35} \mathrm{BNF}$, nal. 2176.

${ }^{36} \mathrm{Hemos}$ analizado cincuenta folios, empezando en el f. $355 \mathrm{r}$ (principio del códice actual) y terminando en el 475v cada cinco folios (355r-v, 360r-v, 365r-v...). Se advierte, como suele ser habitual, que algunas secciones contienen muchas más abreviaturas que otras: frente a las 27 que aparecen en el f. 375r-v y las 30 del f. 385r-v, solo hay 4 en el f. 400r-v o ninguna en el f. 410r-v.

${ }^{37} \mathrm{BN}$, mss. 6367

${ }^{38}$ AHN, Códices, 1.989.

${ }^{39}$ Para un estudio de los aspectos codicológicos, $c f$. Romera Iruela 1988.

${ }^{40}$ Fernández Flórez, Herrero de la Fuente 1995; Serna Serna 2007. No obstante, Marta Herrero de la Fuente cree necesario un examen exhaustivo del manuscrito para determinar si todo el libro es obra suya o si intervinieron varias manos.
} 
El uso de abreviaturas por letra sobrepuesta es abundante. Nuestro repaso ha documentado 552 casos tras el examen de 96 folios $^{41}$, lo que equivale a una media de 5-6 abreviaturas por folio. Sin embargo, un análisis minucioso muestra cómo la distribución de las mismas es irregular: mientras que unas secciones presentan en torno a 20 abreviaturas por folio (ff. $5 \mathrm{r}, 5 \mathrm{v}, 6 \mathrm{r}, 6 \mathrm{v}$, $7 \mathrm{r}, 9 \mathrm{v}, 10 \mathrm{r}$ ), otras incluyen en torno a 13 (ff. 115r-125r), y otras contienen una o ninguna (ff. 175r-199v). Estas irregularidades obligan a plantearnos una serie de cuestiones: ¿Es obra de un solo escriba? ¿Hay alguna influencia externa que explique las secciones en las que abundan las abreviaturas por letra sobrepuesta? ¿Existe un patrón maestro-discípulo en la copia del manuscrito? ${ }^{42}$ Todo ello exige un examen pormenorizado del libro ${ }^{43}$.

El estudio de las abreviaturas por letra sobrepuesta en el Becerro confirma lo visto hasta ahora (tabla 7). La presencia de la sílaba tro en el listado puede resultar sorprendente, pero se explica por la asiduidad del nombre propio $\mathrm{Pet}^{\circ}$, a menudo abreviado de ese modo. De la misma manera, la sílaba cri representa un 3\% del total de abreviaturas por letra sobrepuesta, ya que es frecuente que se abrevie en palabras como sciptura, sciptum, etc.

También vinculados a Sahagún encontramos los bifolios de un Beato que se conservan en el Archivo de la Real Chancillería de Valladolid y en la biblioteca del monasterio de Montserrat ${ }^{44}$. El estudio de los bifolios conservados en Valladolid revela 10 casos de abreviaturas por letra sobrepuesta (5 de $q^{i}, 2$ de $q^{i} a, 2$ de $p^{o}$ pheta y 1 de $p^{i}$ mitus), aunque lo que llama la atención es que todos se concentran en una sola columna. Es difícil encontrar un motivo, pues no se trata de la última columna del cuaderno, por lo que no viene provocado por la limitación del espacio, y tampoco parece ser un escriba distinto.

En el mismo archivo se conserva un bifolio de un Leccionario con notación musical ${ }^{45}$ en letra visigótica, donde el copista recurre en quince ocasiones a la letra sobrepuesta para abreviar, así como un fragmento de un

${ }^{41}$ En este caso hemos hecho un muestreo cada cinco folios. Así, hemos estudiado los ff. 1r, $4 \mathrm{v}, 5 \mathrm{r}, 9 \mathrm{v}, 10 \mathrm{r}, 14 \mathrm{v}, 15 \mathrm{r}$... y así sucesivamente hasta el f. 235r.

${ }^{42}$ El estudio del scriptorium de Frankenthal de Cohen-Mushlin (1990) ha mostrado cómo los maestros escribían unas pocas líneas y los discípulos trataban de imitarlas. Aunque, a primera vista, el Becerro no parece favorecer esta hipótesis, merece la pena estudiar los mecanismos de aprendizaje de un monasterio como Sahagún.

${ }^{43}$ A esto debemos añadir el hecho de que el número de abreviaturas por letra sobrepuesta en los diplomas atribuidos a Munius es insignificante. Herrero de la Fuente, Fernández Flórez 2012 , p. 106 dicen que "en sus pergaminos no se permitió licencias ajenas a la escritura visigótica, como podría ser el sistema abreviativo carolino de letras sobrepuestas". De todos modos, hemos encontrado este recurso abreviativo en tres documentos: AHN 892/6 (pro: lín. 10); 892/9 (qui: lín. 1, and mihi: lín. 12); 893/2 (scriptum: lín. 11).

${ }^{44}$ ARCV, Perg., carp. 1, n. ${ }^{\circ}$ 26-27; Montserrat, Biblioteca del Monestir, ms. 793-III.

${ }^{45}$ ARCV, Perg., carp. 180, n. ${ }^{\circ}$ 10. El examen de las abreviaturas por letra sobrepuesta brinda 6 ejemplos de la sílaba qui, 5 de pro, 3 de pri y 1 de que. 
Homiliario con textos de san Agustín ${ }^{46}$, en el que se advierte un uso mucho mayor de este recurso abreviativo, con un total de 49 casos.

Muy frecuente es también el uso de abreviaturas por letra sobrepuesta en un bifolio de los Moralia in Iob conservado en el Archivo Histórico Nacional (lám. 4) ${ }^{47}$. Hemos hallado 91 palabras en que aparece este recurso abreviativo: la grafía $q^{i}$ aparece en 59 ocasiones, tanto por sí sola en el relativo, como al principio ( $q^{i} p p e, q^{i} d e m$ ), en el medio ( $a d q^{i} s i t i, s e q^{i} t u r \ldots$ ) o al final de la palabra $\left(\text { ini }^{i}\right)^{i}$. Hay además 9 casos de $p^{o}, 5$ de ergo, 4 de modo, de $q^{a}$ y de $p^{i}, 3$ de $c^{i}$ y de $p^{a}$. Se trata, pues, de un manuscrito en el que el sistema está bastante desarrollado, aunque conviene reseñar que al lado de estas abreviaturas por letra sobrepuesta encontramos las habituales letras sobrepuestas del mundo visigótico sin valor abreviativo: $q^{v} a s i, q^{v} a$, aliq $a$, etc.

Por el contrario, en el ms. 112 de la Biblioteca Nacional de España, fechado a finales del siglo XI y comienzos del siglo XII, que contiene el Liber Scintillarum junto a otras obras, la presencia de la letra sobrepuesta es muy reducida, pues el escriba la ha empleado solo en $q^{i} s q^{i} s$ en el f. $12 \mathrm{v}, q^{i}$ y $p^{o}$ en el f. 106r y $p^{o}$ pter en el f. 109v.

El Becerro de Valpuesta ${ }^{48}$ incluye textos en letra visigótica y carolina. Los editores lo han fechado en la primera mitad del siglo XII, aunque algunos folios han de ser llevados a la década de 1160 y hay diplomas originales cosidos en el libro. El influjo carolino en las páginas escritas en visigótica es muy reducido en lo relativo a abreviaturas por letra sobrepuesta (solo hay 13). Como es habitual, destaca $q^{i}$ y llama la atención que no hay ningún caso de pro abreviado de esta manera. Cuando analizamos las páginas escritas en minúscula carolina en fechas tempranas, la situación es semejante; de hecho, abreviaturas por letra sobrepuesta para hic, ibi, uir y Marie solo aparecen en la parte más reciente del libro.

En los primeros años del siglo XII se fecha también el cartulario del monasterio de Santa María del Puerto ${ }^{49}$, conforme a la datación ofrecida por su primer editor y los estudios posteriores ${ }^{50}$. La mayoría del libro está escrito en visigótica, salvo unos documentos copiados en una minúscula carolina de mediados del siglo XII (pp. 38, 42, 44, 45-46). El número de abreviaturas por letra sobrepuesta es bastante bajo: hay un caso de $m^{i}$ y $q^{a} m$, dos de $m^{o}$ y de $p^{o}$ y 21 de la sílaba $q^{i}$. Por el contrario, en las 16 líneas escritas en carolina en

\footnotetext{
${ }^{46} \mathrm{ARCV}$, Perg., carp. 52, n. ${ }^{\circ}$ 8. Encontramos abreviaturas como ergo (4), mihi (1) y uero (1), siendo las más habituales la sílaba qui (29), pro (7), quo (6) y pri (1).

${ }^{47}$ AHN, Códices, 1. 1452/11.

${ }^{48}$ AHN, Códices, 1. 1166. Cf. Ruiz Asencio, Ruiz Albi, Herrero Jiménez 2010.

${ }^{49}$ AHN, Códices, 1. 1001.

${ }^{50}$ Serrano Sanz 1918, p. 420; Abad Barrasús 1985, p. 281; Grijuela Gil 2016.
} 
la p. 38 encontramos 20 casos, mucho más diversos $\left(q^{e}, t^{a}, q^{i}, q^{a}, g^{e}, t^{i}-t i b i-\right.$, $x^{i}-$ Christi- y $t^{i}$-tri-), lo que revela la adopción sistemática de la abreviatura por letra sobrepuesta en un plazo de tiempo relativamente breve.

El Tumbo de Lorvão o Liber testamentorum coenobii Laurbanen$s i s^{51}$ ha sido datado por sus editores entre 1117 y 1120 , y, como en el caso del Becerro de Valpuesta, intervinieron en su redacción numerosas manos, tanto en escritura visigótica como en carolina. El análisis de las abreviaturas por letra sobrepuesta empleadas en la sección visigótica del Tumbo presenta un patrón similar, con un dominio abrumador de $q^{i}$ y $p^{o}$-más del 73\%-. Aunque el número de abreviaturas de este tipo es mucho mayor (unas 20 por página) en la sección en carolina del final (ff. 45v-47v), probablemente han de fecharse en el último cuarto del siglo XII, por lo que, como en el caso del cartulario anterior, solo sirve para confirmar el triunfo del sistema en un periodo de unos cincuenta años.

Por último, los folios escritos en letra visigótica del manuscrito de la Farsalia de Lucano conservados en la Biblioteca Apostólica Vaticana ${ }^{52}$ presentan nueve ejemplos de abreviatura por letra sobrepuesta, todos ellos atribuibles a un escriba que interviene en la parte final del libro (ff. 117r-118r, $120 \mathrm{r}-\mathrm{v})$. Encontramos la sílaba qui en las palabras $q^{i}, q^{i} \operatorname{dem}$ y $l o q^{i}$, la sílaba $p r o$ en $p^{o}$ pius (sic), $p^{o}$ cul ( 2 veces) y $p^{o}$ fusus, así como la palabra modo (aunque erróneamente abreviada: $m^{\circ} d^{\circ}$ libet).

El repaso de códices y fragmentos en letra visigótica de fines del siglo XI y comienzos del siglo XII tiende a confirmar lo hallado en el campo documental (tablas 6-11). Por un lado, hay muchas diferencias entre unos escribas y otros, aunque, por otro, el patrón de uso es similar: el dominio de $q^{i}$, $p^{o}$ y $p^{i}$ es abrumador, normalmente superando el $80 \%$ de los casos (y $q^{i}$ supone más del 40\%). Las anomalías suelen responder a peculiaridades del libro, como en el caso de $q^{a}$ en el Poenitentiale o de $t^{t}$ en el Becerro de Sahagún.

El estudio sobre los códices litúrgicos del siglo XV de Bozzolo, Coq, Muzerelle y Ornato y el de obras jurídicas de Giovè Marchioli insisten en la necesidad de prestar atención a la parte de la palabra abreviada, a su posición en el renglón, etc ${ }^{53}$. En el repaso que hemos realizado la posición en el renglón no parece jugar ningún papel, pues encontramos abreviaturas al comienzo, en el centro y al final del renglón, así como al comienzo del folio y al final del mismo (ni siquiera el final de un cuaderno varía significativamente el número de abreviaturas). Asimismo, la posición dentro de la palabra tampoco resulta

\footnotetext{
${ }^{51}$ ANTT, MSML/B/49.

${ }^{52}$ BAV, Ott. Lat. 1210, ff. 41r-72v, 74r-124v.

${ }^{53}$ Bozzolo, et al. 1990, pp. 20-21; Giovè Marchioli 1991, pp. 19-20.
} 
determinante; el hecho de que aparezca sobre todo en la primera sílaba deriva de que el número de palabras que comienzan con qui o pro es mucho mayor que el de palabras en que esas sílabas aparecen en medio o al final.

\section{EL LARGO PROCESO DE ADOPCIÓN DE LA ABREVIATURA CAROLINA POR LETRA SOBREPUESTA}

Teresa de Robertis ha planteado que, si bien es inevitable estudiar las abreviaturas a partir de las figurae estáticas, no debemos dejar de intentar remontarnos al momento en el que el escriba las pone por escrito ${ }^{54}$. Así pues, ahora hemos de retomar la pregunta que nos hacíamos al comienzo: ¿cómo percibieron los escribas el cambio gráfico desde la escritura visigótica a la carolina?

Mientras que el recurso a las abreviaturas por letra sobrepuesta era verdaderamente excepcional en 1020, cuando Ermegildus lo empleó por vez primera en un documento de Sahagún, hacia 1120 se había extendido por todo el territorio que analizamos. Podemos, pues, comenzar preguntándonos, con Erik Kwakkel, cómo un rasgo paleográfico pasa de ser algo idiosincrático a ser la norma ${ }^{55}$.

\section{1. ¿Cómo adoptaron los escribas visigóticos las abreviaturas por letra sobrepuesta?}

Una primera respuesta a la pregunta de Kwakkel es: lenta e irregularmente. El anterior análisis ha mostrado que fue un proceso gradual e irregular, el cual solo se aceleró en la última década del siglo XI. En cualquier caso, más relevante que su lentitud es su irregularidad. Tal como señalamos, antes de 1090 este sistema solo aparece en documentación de León, Sahagún y Eslonza, lo que sugeriría que su introducción estuvo relacionada con scriptoria próximos a las esferas de poder. En este sentido, la pronta adopción de este tipo de abreviaturas en un núcleo menor como Valladolid ha de verse en conexión con la presencia del conde Pedro Ansúrez, un destacado noble con vínculos con la familia que gobernaba Urgel. Más aún, la adopción de este recurso fue irregular incluso en el mismo scriptorium puesto que, mientras que algunos escribas no lo emplearon, otros hicieron presto uso de él. Por lo

\footnotetext{
${ }^{54}$ De Robertis 1993, p. 164.

${ }^{55}$ Kwakkel 2018, p. 38.
} 
tanto, es preciso llevar a cabo un análisis detenido de los escribas de los diferentes scriptoria para ver sus opciones, su evolución... Por desgracia, dada su dificultad, no son frecuentes los estudios sobre los escribas de un mismo scriptorium y, en muchos casos, todavía se encuentran pendientes ${ }^{56}$. Cuando prestamos atención a un determinado escriba, es posible discernir pequeños cambios a lo largo del tiempo. Por ejemplo, en el monasterio de San Pedro de Eslonza, Iohannes es el rogatario de cuatro documentos fechados en 1095 y 1096. En el más antiguo de ellos (AHN 960/9) encontramos varias abreviaturas por letra sobrepuesta $\left(p^{o}, q^{i}, p^{a}\right.$ y $\left.p^{i}\right)$, así como cinco casos de qui visigótico (lám. 4). En el segundo documento (AHN 960/12) solo hay dos ejemplos de qui visigótico y uno en el tercer documento (AHN 960/12). Finalmente, el último documento (AHN 960/13) no presenta ningún caso de qui visigótico, en tanto que encontramos abreviaturas por letra sobrepuesta como $p^{a}, p^{o}, p^{i}, q^{a}$ and $q^{\circ}$. En el monasterio de Sahagún, la ausencia de este recurso en los nueve documentos atribuidos a un Petrus (1100-1107) contrasta con lo que encontramos en escribas como Pelagius (1101-1104), que utiliza 20 veces la letra sobrepuesta en cuatro diplomas: $q^{i}, p^{o}, p^{i}, q^{a}, q^{o}, u^{o}$, o Martinus (1106-1116), que hace uso de un abanico de abreviaturas aún más amplio: $q^{a}, p^{a}, q^{i}, t^{a}, t^{i}-t i b i-$, $q^{o}, u^{o}$ (para un total de 21 en cuatro documentos). Resulta, no obstante, difícil determinar si estas diferencias se deben a la fidelidad a la tradición anterior, a la incapacidad o poca disposición a la hora de adaptarse a los cambios o a la existencia de redes de escribas que influían en uno u otro sentido.

Cuando comparamos la situación de estos territorios con lo sucedido en Francia algunas décadas antes, advertimos cómo también allí es posible detectar la lentitud -y en particular la irregularidad- de su uso en la redacción de documentos durante la segunda mitad del siglo $\mathrm{XI}^{57}$. El repaso de dichos documentos ha mostrado que, hasta 1070, la mitad de la documentación (50/100) no presenta este tipo de abreviaturas; por el contrario, solo el 24,5\% (27/110) no las incluye entre 1075 y 1090.

Ahora bien, en el lento e irregular proceso que hizo que este sistema abreviativo se convirtiese en norma durante el siglo XII, ¿cuán difícil resultó a los escribas visigóticos adaptarse al nuevo sistema?

\footnotetext{
${ }^{56}$ Hay algunas felices excepciones que brindan un estudio riguroso de los escribas: Castro Correa 2012 .

${ }^{57}$ Usando la colección de las Chartes originales antérieures à 1121 conservées en France incluidas en la plataforma Telma (http://www.cn-telma.fr/), hemos repasado cada cinco años todos los documentos que incluían una imagen digital entre 1050 y 1090. Los resultados del análisis están resumidos en tablas 12 y 13. La situación es algo diferente en el caso de los códices, pues el estudio de algunos manuscritos muestra que este sistema estaba plenamente establecido hacia mediados del siglo XI: BNF, lat. 5256 (fechado entre 1046 y 1055); lat. 3680 (fechado en 1051-1110); nal. 1444 (fechado entre 1081 y 1100); lat. 2226 (fechado entre 1120-1150).
} 
Una posible forma de explorar esta cuestión consiste en estudiar los errores cometidos por los escribas al usar tales abreviaturas. Sin embargo, el número de errores es sorprendentemente pequeño. Tras repasar la documentación indicada, solo hemos hallado ocho ${ }^{58}$, lo que pone de manifiesto un cierto dominio del sistema por aquellos escribas que recurrieron a él. En este sentido, podemos preguntarnos qué sucede en un manuscrito como el De fide catholica de Isidoro (lám. 5) ${ }^{59}:$ ¿se trata de un manuscrito plagado de errores o es un intento consciente de ahorrar espacio escribiendo letras sobrepuestas sin valor abreviativo? El libro incluye 25 palabras y sílabas abreviadas correctamente conforme al sistema usual $\left(q^{i}, q^{o}, u^{o}\right)$, pero $i$ sobrepuesta tiende a no servir de abreviatura: por ejemplo, solo en el f. 42r encontramos dos casos de $q u i$ abreviado correctamente por letra sobrepuesta $\left(q^{i}\right)$, pero semine, idcirco,

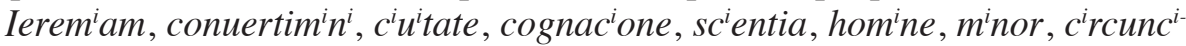
sione, prepucio, c'iuitatem, cognacionem, Iherem ${ }^{i} a s$, seruire y exercituum están escritas con una $i$ sobrepuesta sin abreviar nada. Un fenómeno similar, aunque a una escala mucho menor, se halla en un documento de la Catedral de Valladolid (25/2), donde la $i$ de dampnatione y $u^{i}$ sores está sobrepuesta pero no tiene valor abreviativo. En el repaso de códices franceses coetáneos hemos encontrado otro manuscrito que presenta la misma singularidad: un códice misceláneo escrito hacia mediados del siglo XI tal vez en Carcasona ${ }^{60}$. Hay varios casos de palabras en los que algunas vocales (fundamental, pero no exclusivamente $i$ y $o$ ) están sobrepuestas sin servir de abreviaturas: Marcian ${ }^{i}$, $\operatorname{Dioclec}^{i} a n^{o}$ (f. 7r), Rom ${ }^{a} n i$ (f. 7v), hon re (f. 24r), etc. Además, el libro abrevia sistemáticamente quomodo como $q^{o} m^{o} d^{o}$, haciendo uso de letras sobrepuestas con valor abreviativo y sin él. Así pues, la existencia de una serie de códices y documentos que presentan esta singularidad quizá refleje cómo algunos escribas, en un periodo de cambio, ensayaron el uso de letras sobrepuestas hasta que el sistema quedó finalmente fijado.

Asimismo, cuando los escribas visigóticos entraron en contacto con el mundo de las abreviaturas carolinas, la letra sobrepuesta no era una novedad absoluta, puesto que ya la empleaban de distintos modos (lám. 6). Como en el caso de otras escrituras coetáneas, la letra sobrepuesta se usaba habitual-

${ }^{58}$ ACL 364 (1080): $q u^{i} s$ ( $i$ está escrita sobre $u$ ); AHN 886/3 (1089): $n^{e} q^{e}$ (las dos $e$ están sobrepuestas); AHN 888/1 (1095): $q u^{o} s$ (o está escrita sobre $u$ ); AHN 891/7 (1103): $p r^{o} p^{i} n q u^{i} s$ (todas las vocales están sobrepuestas); ACL 296 (1117): quom ${ }^{\circ} d o$ (do se añade después de la abreviatura de modo); AHN 960/6 (¿1123? ¿o más bien fines del siglo XI?): qu $u^{i}(i$ está escrita sobre $u$ ); BAV, Ott. Lat. 1210, f. 117v: $m^{\circ} d^{o}$ libet .

${ }^{59} \mathrm{BN}$, mss. 4339. La obra, cuyo título completo es De fide catholica ex Veteri et Novo Testamento contra Iudaeos ad Florentinam sororem, se fecha en el siglo XI y está escrita en su mayor parte en escritura visigótica (78 folios de 90) con algunas abreviaturas carolinas.

${ }^{60} \mathrm{BNF}$, Lat. 5256. 
mente para abreviar numerales cardinales $\left(M^{e}, C^{m}, V^{e}, I I I I^{o r} \ldots\right)$ y ordinales $\left(M^{a}\right.$, $X^{a}$...). Además, dichos escribas solían escribir la $u$ sobrepuesta en combinaciones como $t^{v} r$ o $t^{v} s$ y en los relativos $\left(q^{v} i, q^{v} O, q^{v} a\right)^{61}$. Más rara es la aparición de otras vocales, sin bien hay casos de $i$ y $o$ sobrepuestas (por ejemplo, ACL $228 ; 252)^{62}$.

Un elemento adicional que pudo haber ayudado a los escribas en la adopción del nuevo sistema es la existencia de ejemplares de códices extranjeros y de formularios. Copiar de un códice extranjero explicaría la aparición de abreviaturas por letra sobrepuesta en un libro visigótico como el Glosario de San Millán de la Cogolla ${ }^{63}$, donde, por ejemplo, encontramos abreviados por este sistema $n^{c}-$ nunc- (f. 90v) y $m^{o}-$ modo- (f. 94r). Fue escrito en el 964 y es muy posible que las abreviaturas ya estuviesen presentes en el ejemplar del que copió el escriba. El hecho de que el Glosario de Silos ${ }^{64}$ también abrevie de esta manera nunc (f. 108r) y modo (f. 113r), y solo esas palabras, parece confirmar la presencia de la abreviatura en el modelo.

En el caso de documentos, el uso de formularios está bien atestiguado desde fechas tempranas ${ }^{65}$. No obstante, lo que nos interesa es si estos ya incluían abreviaturas por letra sobrepuesta. La repetición de abreviaturas en expresiones formularias como in $p^{i} m i s$, si $q^{i} s$, propinq ${ }^{i} s$, etc. tienden a respaldar esta hipótesis. Además, tras revisar la documentación, tres documentos en carolina de la Catedral de Valladolid fechados en 1113 y 1114 escritos por Martinus (ACV 12/1A; 18/10; 10/57) pueden brindar un testimonio más elocuente. En los tres documentos, una de las cláusulas sancionales ofrece las mismas abreviaturas: quisq ${ }^{i}$, propinq $^{i} s$ y $q^{i}$ (lám. 7). Dadas las diversas posibilidades, es hasta cierto punto llamativo que el autor recurra a abreviar de idéntica manera las mismas palabras ${ }^{66}$. Por otro lado, el uso regular de este sistema en las fórmulas si $q^{i}$ s y $p^{o}$ testes del Becerro de Sahagún puede también deberse a que Munius dispusiera de algún tipo de formulario al copiar los documentos.

En relación con Munius, el Liber testamentorum sancti Facundi nos brinda la oportunidad de explorar lo que hizo al copiar los documentos originales en el cartulario. Aquí no nos preocupa su fidelidad en términos de

\footnotetext{
${ }^{61}$ Algo que también aparece en la documentación francesa e italiana: Parigino 1993, p. 307.

${ }^{62} \mathrm{Ha}$ de advertirse que la $o$ sobrepuesta puede haberse insertado con posterioridad a fin de corregir un error previo.

${ }^{63}$ RAH, Em. 46. García Turza, García Turza 1997.

${ }^{64}$ BNF, nal. 1296.

${ }^{65}$ Fernández Flórez, Herrero de la Fuente 2009; Fernández Flórez 2016, pp. 51-52.

${ }^{66}$ Podemos preguntarnos, en cualquier caso, si la exactitud deriva de la existencia de un formulario previo o si Martinus tenía a su disposición el primer documento, que entregaría después, mientras escribía los otros dos diplomas.
} 
contenido, sino sus opciones a nivel gráfico. En muchos casos actualizó las abreviaturas que halló en los originales; así, el signo visigótico de -is lo sustituyó por una línea sobrepuesta y el signo de - us visigótico lo reemplazó por su homólogo carolino. En relación con nuestro análisis, vemos cómo, por lo general, tiende a añadirlas cuando no las había en el documento original (lám. $8)^{67}$ y cuando estaban abreviadas conforme a las convenciones visigóticas ${ }^{68}$. Sin embargo, más sorprendente es el hecho de que Munius omita abreviaturas por letra sobrepuesta presentes en el diploma original ${ }^{69}$. Lo que hallamos, por lo tanto, es que no hay una pauta firme en la tarea de Munius como copista.

El cotejo de los diplomas originales llegados a nosotros y de su copia en el Liber testamentorum coenobii Laurbanesis ofrece resultados parecidos. Sus autores tienden a emplear este tipo de abreviaturas cuando no había ninguna en los documentos que copian, en tanto que en ocasiones no incluyen las que había en los originales en su copia.

\section{2. ¿Por qué adoptaron los escribas visigóticos las abreviaturas por letra sobrepuesta?}

Un argumento tradicional a favor del uso de abreviaturas es la necesidad de ahorrar tiempo y espacio (Isidoro, Etym. 1, 23, 1). Sin embargo, una ojeada a muchos códices y documentos visigóticos muestra que tal necesidad no parece jugar un papel destacado en la adopción del sistema carolino de abreviación a finales del siglo XI y comienzos del XII. De hecho, el interlineado y los márgenes aumentan durante este periodo.

También se ha postulado que la razón que explica la llegada de la escritura carolina a León y a Castilla -y en consecuencia de su sistema abreviativo- es la imposición externa ${ }^{70}$. En este sentido, el uso de la escritura ca-

\footnotetext{
${ }^{67}$ Así, por ejemplo, AHN 879/10 no tenía abreviaturas; sin embargo, cuando Munius copió el texto en el f. 70r del Liber abrevió por letra sobrepuesta Pimitiuo, qinta y Velasq ${ }^{i} z$. De forma parecida, la sílaba qui de la palabra inq ${ }^{i}$ etauerit en el f. 81 del Becerro no estaba abreviada en el original (AHN 883/23). Una vez más, AHN 886/18 no tenía abreviaturas, pero Munius recurrió a qui y pri sobrepuestos en seis ocasiones al copiarlo en el f. 141v del Liber. En este caso, incluso cambió algunas palabras: mientras que el original reflejaba los tradicionales apellidos como Rodrigiz y Domengiz, el autor del Liber los convirtió en Rodriq ${ }^{i} z$ y Domenq ${ }^{i}$.

${ }^{68}$ Por ejemplo, la grafía qui de la palabra antiquissimis en AHN 884/10, de la palabra quis en 886/14 y de la palabra Velasquiz en AHN 886/19 están abreviadas conforme al sistema visigótico. Las tres las abrevia usando $i$ sobrepuesta en el Becerro (ff. 163r-v, 66r, 18v-19r, respectivamente).

${ }^{69}$ Por ejemplo, mientras que tibi está abreviado mediante letra sobrepuesta en AHN 886/14, aparece escrito íntegramente en el f. 66r del Becerro.

${ }^{70}$ Sin embargo, David (1947, pp. 431-439) y Gambra (1997, p. 128), entre otros, han puesto en tela de juicio la existencia de un canon en el Concilio de León de 1090 acerca del abandono
} 
rolina se ha vinculado a la sustitución de la liturgia mozárabe tradicional por el rito romano y a la expansión del monacato cluniacense por la región. Sin embargo, por un lado, los primeros testimonios de este tipo de abreviatura son anteriores tanto al establecimiento de Cluny en el monasterio de San Isidro de Dueñas (Palencia) en 1073 como a las distintas cartas, disposiciones y maquinaciones del papa Gregorio VII (1073-1085) en su intento de imponer un rito unificado en León y Castilla ${ }^{71}$. Por otro lado, la adopción de la liturgia romana no conllevaba necesariamente el uso de la minúscula carolina, dado que hay ejemplos de códices litúrgicos con el rito romano escritos en visigóti$\mathrm{Ca}^{72}$. De hecho, la longevidad misma de la escritura visigótica en el occidente de la Península Ibérica descarta el éxito de cualquier imposición formal por parte de las autoridades laicas o eclesiásticas. Así pues, la escritura visigótica es la única empleada en la documentación del rey Alfonso $\mathrm{VI}^{73}$, la utilizan algunos escribas de la cancillería de la reina Urraca (1109-1126) ${ }^{74}$ y aún sobrevive en algunos documentos de Alfonso VII (1126-1157) ${ }^{75}$. No obstante, el impacto de Cluny en toda la cristiandad occidental es innegable, y en el caso de León y Castilla puede deducirse del número de obispos y canónigos del periodo con lazos con el monasterio francés o sus monjes ${ }^{76}$. Su llegada vino acompañada de una nueva liturgia, de nuevas obras bíblicas y teológicas (como la de Buchardus), etc. La presencia de códices en escritura carolina en Cataluña ha sido atentamente analizada y existe alguna vista panorámica al respecto $^{77}$. La situación es muy diferente en el caso del occidente peninsular, donde los trabajos sobre esta cuestión son bastante escasos y brindan información de carácter más local ${ }^{78}$. Más aún, los estudiosos han señalado cómo no solo la letra, sino también -y antes- la estética de los diplomas carolinos se introdujo en los documentos visigóticos ${ }^{79}$. El nuevo tamaño y disposición de la página o del documento, el aumento de los espacios en blanco, la separación entre el cuerpo del texto y los signos y marcas de validación,

\footnotetext{
de la escritura visigótica en favor de la carolina. Ver al respecto el artículo de A. Castro en este monográfico.

${ }^{71} \mathrm{Al}$ respecto, $c f$. Reglero de la Fuente 2008; Montenegro 2009; Rucquoi 2010.

${ }^{72}$ Castro Correa 2016, pp. 213-215.

${ }^{73}$ Gambra 1997, pp. 129-137.

${ }^{74}$ Ruiz Albi 2003, pp. 274-278.

${ }^{75}$ Aunque desconocemos una edición íntegra de los documentos de Alfonso VII en la que se mencione el tipo de escritura, algunos documentos fueron redactados en letra visigótica: Calleja Puerta 2011,p. 137.

${ }^{76}$ Reglero de la Fuente 2008, pp. 323-355.

${ }^{77}$ Mundó 1988.

${ }^{78}$ Gonzálvez Ruiz 1997, pp. 77-84; Vezin 2003, pp. 217-222; Miranda García 2015.

${ }^{79}$ Ostolaza Elizondo 1990, p. 162; Ruiz Asencio 2008, pp. 196-197.
} 
son todos ellos elementos vinculados a la difusión de la estética carolina entre los escribas visigóticos.

Por último, cualquier intento de explicar el uso de abreviaturas no puede eludir la consideración de factores psicolingüísticos. Así, estas han de contemplarse no solo desde la perspectiva del escritor, sino también del lector ${ }^{80}$. Cuando un escriba recurre a una abreviatura, ha de estar seguro de que la audiencia a la que se dirige será capaz de descifrarla. Puesto que la lectura conlleva movimientos breves y veloces del ojo, seguidos de una pausa, las abreviaturas son una manera de facilitar la lectura, pues el lector puede percibir de un vistazo una idea que requeriría mucho más espacio si se escribiera íntegramente. Sin embargo, tal como señala Sánchez Prieto, este fenómeno es solo válido en el caso de palabras usadas con frecuencia ${ }^{81}$. A ello hemos de añadir las observaciones de Caligiani y Parigino acerca del hecho de que durante la Antigüedad Tardía y la Edad Media la sílaba se convirtió en la unidad básica de abreviación ${ }^{82}$.

Todas estas observaciones sirven para explicar diversos aspectos de la abreviatura por letra sobrepuesta en el periodo que estudiamos. Primero, el número total de abreviaturas en códices y documentos fue relativamente bajo durante los últimos años del siglo XI y los primeros del siglo XII. Y segundo, las abreviaturas se limitaban a un puñado de combinaciones. Esto se pone de manifiesto antes en la manera en que se empleaban en códices redactados en Europa desde los siglos IX y X, tal como un rápido análisis de algunas obras revela. Por ejemplo, el escriba de la Vita Sancti Columbae, compuesto en la abadía de St. Gall en el tercer cuarto del siglo IX, usó este sistema para abreviar solo la sílaba pra y en todos los casos forma parte de la palabra $s^{a}{ }^{a}$ o de

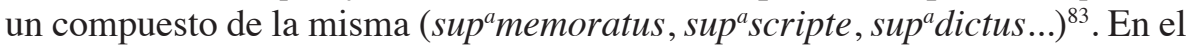
Comentario al Libro de los Reyes de Rábano Mauro, escrito hacia 920-925, todas las abreviaturas por letra sobrepuesta son sílabas en las que aparece la letra $q$ (13 casos de $q^{i}, 7$ de $q^{a}$ y 5 de $\left.q^{o}\right)^{84}$. El examen pormenorizado de las cien primeras páginas de CSang. 80, una Biblia fechada en el siglo X, brinda resultados parecidos: las abreviaturas son bien la sílaba pra en la palabra sup ${ }^{a}$ o bien diversas combinaciones silábicas con la letra $q$ (18 casos de $q^{i}, 3$ de $q^{o}$, y 2 de $\left.q^{a}\right)^{85}$. Mientras que el número total de abreviaturas por letra sobrepuesta en los códices que hemos mencionado es en cierta medida sorprendentemente

\footnotetext{
${ }^{80}$ Giovè Marchioli 1991, p. 23; Giovè Marchioli 1993, pp. 109-125.

${ }^{81}$ Sánchez Prieto 2001, p. 161. Estudios recientes (Perea, Acha, Carreiras 2009) han insistido en la necesidad de considerar factores como la frecuencia y la repetición de la palabra.

${ }^{82}$ Caligiani 1993, pp. 281-287; Parigino 1993, p. 332.

${ }^{83}$ CSang. 555, pp. 64, 65, 68, 78, 83, 108. La palabra aqilonem en la p. 108 parece ser un añadido posterior.

${ }^{84}$ CSang. 284.

${ }^{85}$ CSang. 80.
} 
bajo, hay una tendencia creciente en su uso: 7 casos en la Vita (en 170 páginas), 26 casos en el Comentario de Rábano Mauro (en 188 páginas) y 26 ejemplos en la Biblia (en 100 páginas).

Cuando prestamos atención a León y Castilla en los primeros momentos de la introducción de las abreviaturas carolinas, hallamos una pauta semejante. Por un lado, como hemos visto, el número total de abreviaturas es bastante reducido hasta la última década del siglo XI. Por otro lado, las abreviaturas que aparecen corresponden mayoritariamente a ocho palabras y sílabas $\left(m^{o}, t^{i}-t i b i-, p^{a}, p^{i}, p^{o}, q^{a}, q^{i}\right.$ y $\left.q^{o}\right)$. Por lo tanto, la praxis en el uso de las abreviaturas por letra sobrepuesta tal como se desarrolló en el periodo de introducción de la escritura carolina coincide con los rasgos psicológicos que los expertos consideran básicos: frecuencia, repetición y primacía de la sílaba.

\section{CONCLUSIONES}

En primer lugar, a la luz del estudio realizado, creemos que la introducción de la letra sobrepuesta como recurso abreviativo en el territorio analizado es algo posterior a lo que tradicionalmente se había asumido, generalizándose a partir de la última década del siglo XI.

En segundo lugar, la aparición de este recurso en textos visigóticos nos habla de un primer momento de transición en el que los escribas están familiarizados con el sistema abreviativo carolino, aun cuando siguen aferrados a la escritura visigótica. Ello hace que durante varias décadas convivan los dos sistemas en documentos y códices y que paulatinamente se abandone el sistema visigótico por el carolino.

En última instancia, la adopción generalizada de este sistema durante el siglo XII tuvo que ver con el paso del tiempo y con el descubrimiento de su eficacia. Cuando en los territorios de León y Castilla las viejas camarillas de escribas visigóticos fueron sustituidas por otras de "nativos carolinos", el sistema abreviativo se incorporó de forma natural en sus hábitos de escritura. Ello se vio facilitado por el hecho de que el proceso había comenzado por un puñado de sílabas y palabras muy comunes que resultaban fáciles de recordar y aplicar. Sin embargo, los primeros pasos de dicho proceso se caracterizaron por la impredecibilidad y la indolencia de la naturaleza humana. Los escribas no solo hicieron lo que quisieron al recurrir a las abreviaturas por letra sobrepuesta; algunos decidieron no molestarse en aprender un sistema nuevo y extranjero. Sin embargo, lo que las imposiciones formales no lograron, lo hizo la simplicidad y utilidad del sistema. De este modo, a finales del siglo XII, el universo gráfico de León y Castilla estaba preparado para la explosión de abreviaturas por letra sobrepuesta que acompañó el desarrollo de las universidades. 


\section{TABLAS}

Tabla 1. Documentos (Doc.) y abreviaturas por letra sobrepuesta (Abr.) por década

\begin{tabular}{|r|c|c|c|c|c|c|c|c|c|c|c|c|c|}
\hline & \multicolumn{2}{|c|}{-1070} & \multicolumn{2}{|c|}{$1071-1080$} & $1081-1090$ & $1091-1100$ & \multicolumn{2}{|c|}{$1101-110$} & \multicolumn{2}{|c|}{$1111-1120$} \\
\hline & DOC. & ABR. & DOC. & ABR. & DOC. & ABR. & DOC. & ABR. & DOC. & ABR. & DOC. & ABR. \\
\hline LEÓN & & & 2 & 7 & 4 & 10 & 8 & 41 & 6 & 44 & 13 & 88 \\
\hline SAHAGÚN & 2 & 2 & 1 & 1 & 5 & 13 & 21 & 80 & 15 & 96 & 17 & 141 \\
\hline BURGOS & & & & & & & 1 & 3 & 1 & 7 & 1 & 7 \\
\hline LUGO & & & & & & & 3 & 8 & 2 & 9 & 2 & 4 \\
\hline PALENCIA & & & & & 1 & 5 & & & & & & \\
\hline VALLADOLID & & & & & & & 1 & 10 & 2 & 5 & 5 & 31 \\
\hline ESLONZA & & & 1 & 10 & 1 & 6 & 11 & 79 & 2 & 6 & 2 & 9 \\
\hline OTERO & & & & & & 3 & 9 & 4 & 12 & 2 & 11 \\
\hline OÑA & & & & & & & 1 & 2 & 2 & 11 & 1 & 2 \\
\hline
\end{tabular}

Tabla 2. Lista de sílabas y palabras abreviadas en documentos visigóticos y carolinos

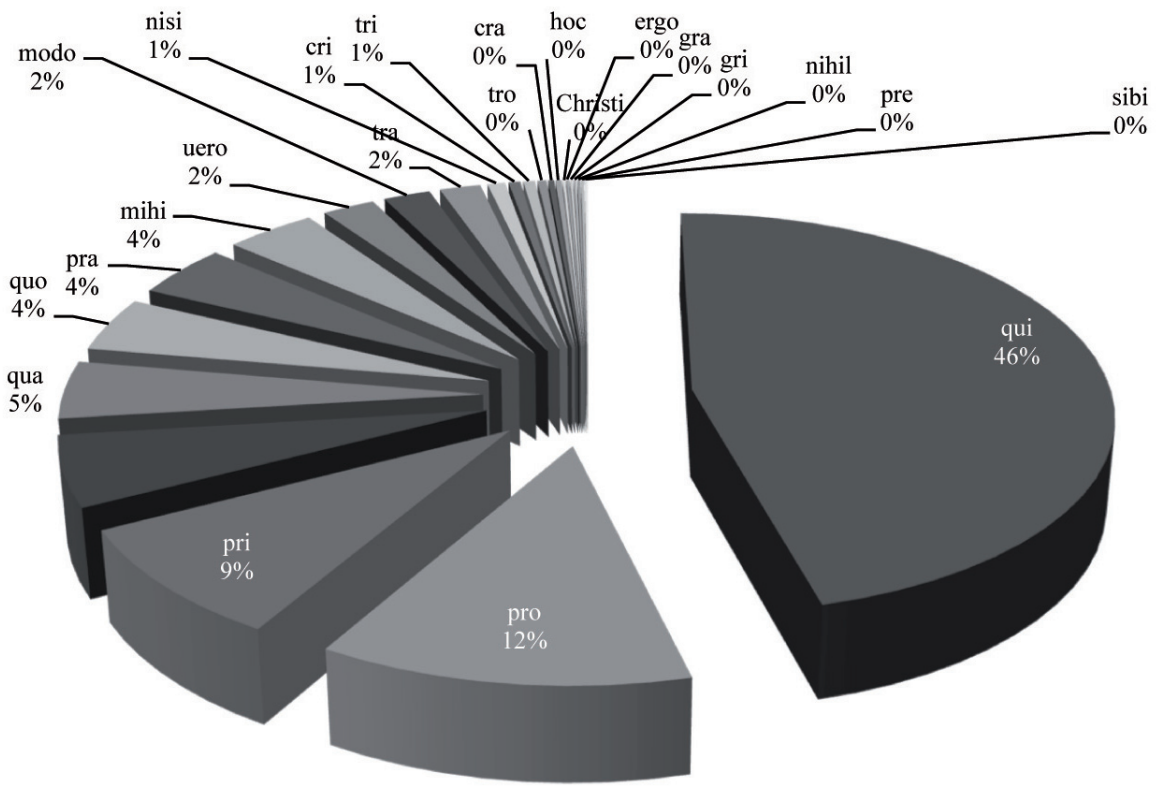


Tabla 3. Lista de abreviaturas por letra sobrepuesta en documentos visigóticos

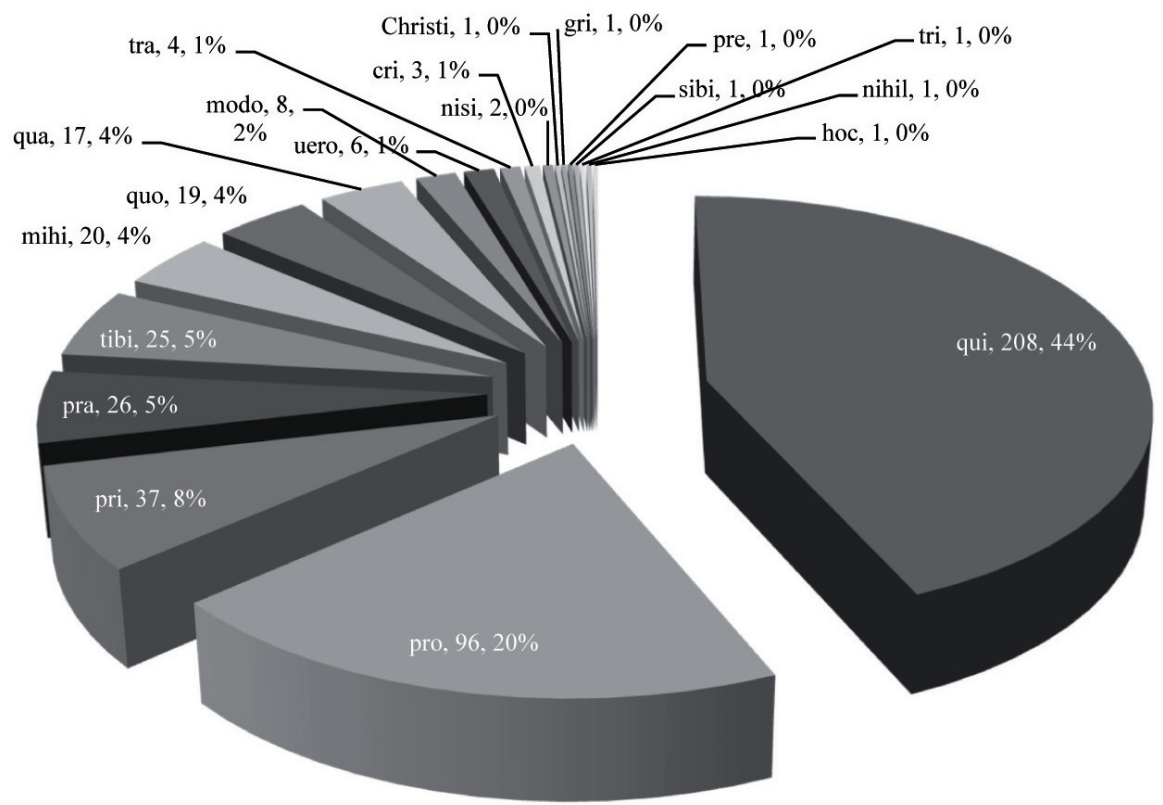

Tabla 4. Evolución de las principales abreviaturas por letra sobrepuesta

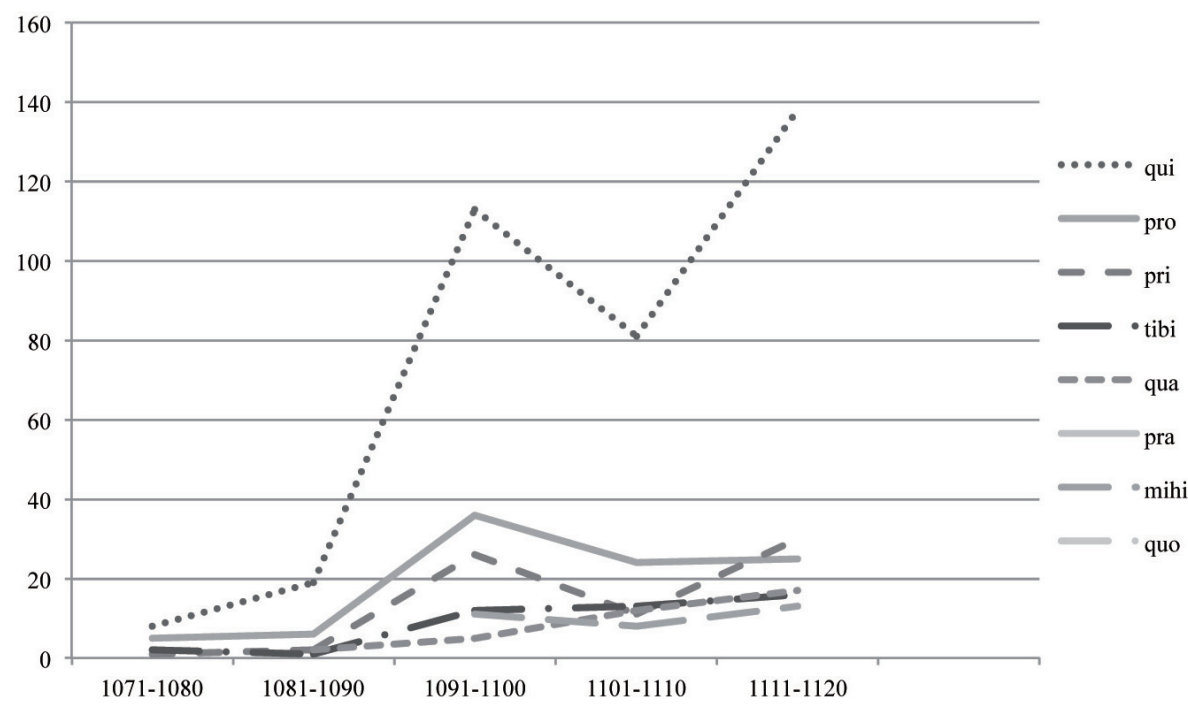


Tabla 5. Evolución del número y tipo de abreviaturas por letra sobrepuesta

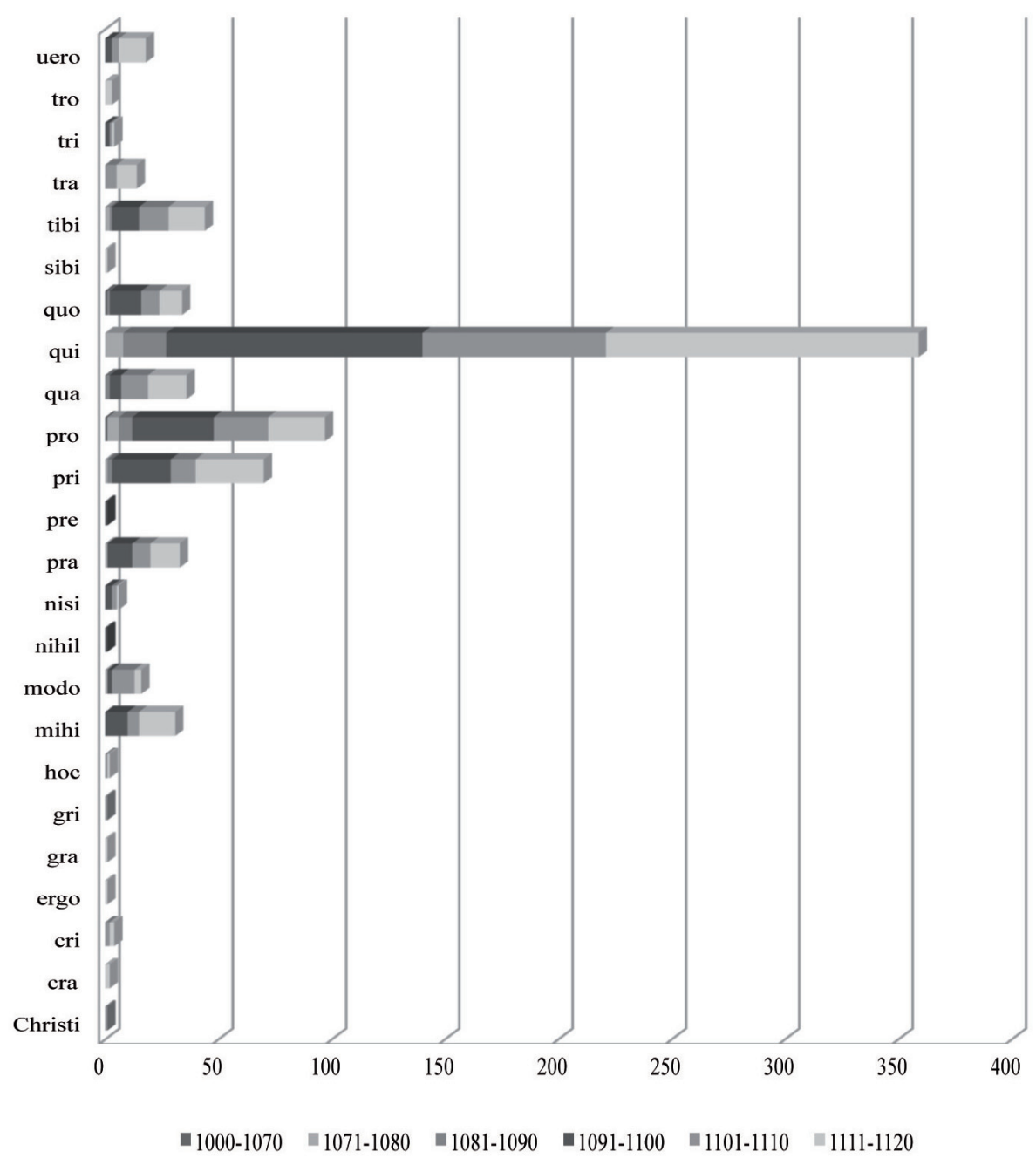


Tabla 6. Abreviaturas por letra sobrepuesta en el Poenitentiale de Burchardus (BN, mss. 6367)

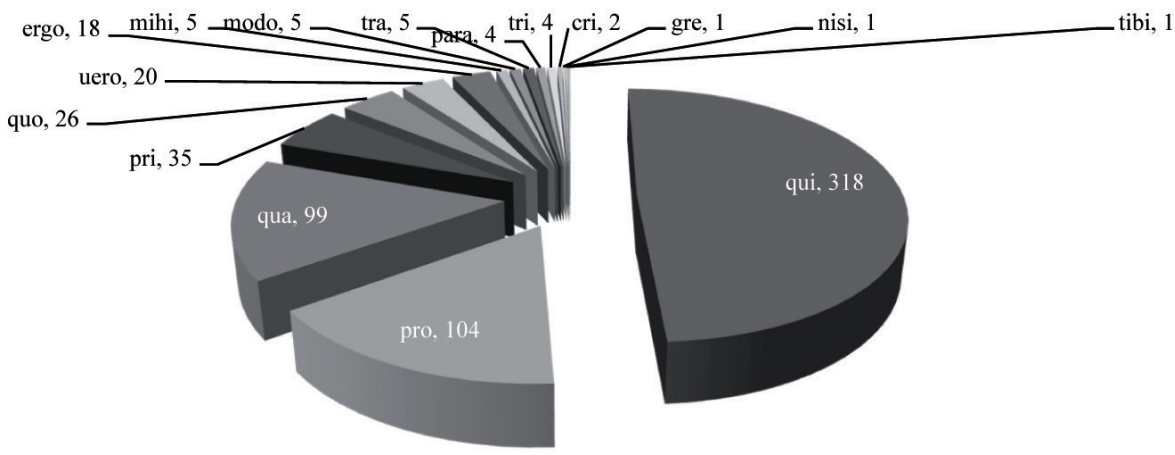

Tabla 7. Abreviaturas por letra sobrepuesta en el Becerro de Sahagún (AHN, Códices, 1.989)

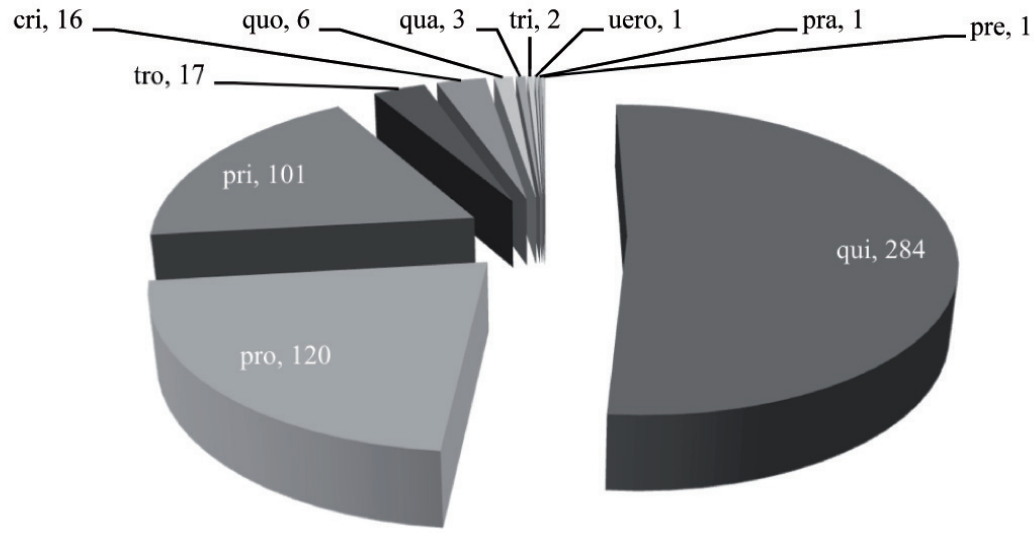

Tabla 8. Abreviaturas por letra sobrepuesta en las secciones visigóticas del Cartulario de Valpuesta (AHN, Códices, 1. 1166)

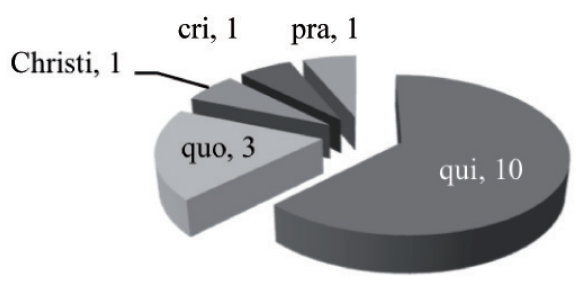


Tabla 9. Abreviaturas por letra sobrepuesta en las secciones en carolina del Cartulario de Valpuesta (AHN, Códices, 1. 1166)

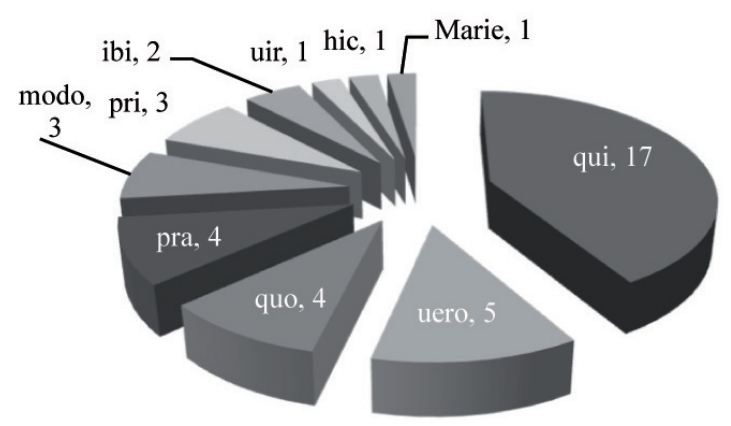

Tabla 10. Abreviaturas por letra sobrepuesta

en el Cartulario de Santa María del Puerto (AHN, Códices, 1, 1001)

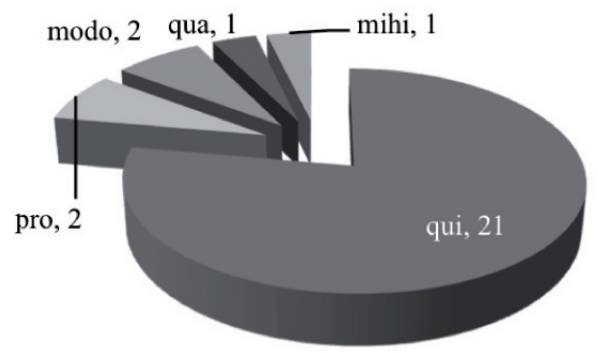

Tabla 11. Abreviaturas por letra sobrepuesta en las secciones visigóticas del Tumbo de Lorvão (PT/TT/MSML/B/49)

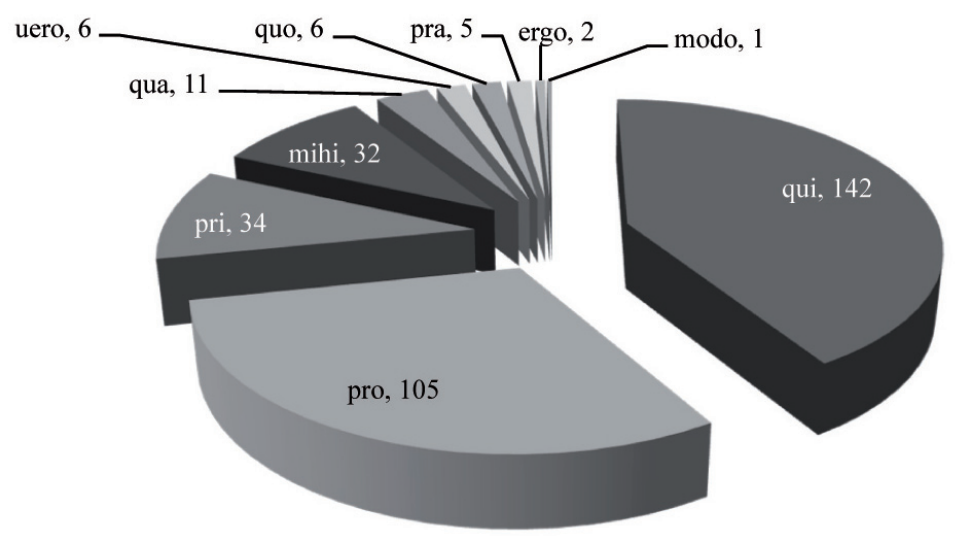


Tabla 12. Número total de documentos y abreviaturas por letra sobrepuesta cada cinco años y número de correspondiente en cada documento

(a partir de la Plataforma Telma: http://www.cn-telma.fr/)

\begin{tabular}{|c|c|c|c|c|c|c|c|c|}
\hline & $\begin{array}{c}\mathrm{N}^{\mathrm{o}} \\
\text { Docs. }\end{array}$ & $\begin{array}{c}\mathrm{N}^{\mathrm{T}} \\
\text { TotAL } \\
\text { ABR. }\end{array}$ & $\begin{array}{c}\text { DoC. } \\
\text { 0 ABR. }\end{array}$ & $\begin{array}{c}\text { DoC. } \\
1-5 \text { ABR. }\end{array}$ & $\begin{array}{c}\text { DoC. } \\
6-10 \text { ABR. }\end{array}$ & $\begin{array}{c}\text { DoC. } \\
\text { 11-15 ABR. }\end{array}$ & $\begin{array}{c}\text { DOC. } \\
16-20 \text { ABR. }\end{array}$ & $\begin{array}{c}\text { DoC. } \\
+20 \text { ABR. }\end{array}$ \\
\hline 1050 & 20 & 17 & 14 & 4 & 2 & 0 & 0 & 0 \\
\hline 1055 & 9 & 17 & 5 & 2 & 2 & 0 & 0 & 0 \\
\hline 1060 & 36 & 81 & 16 & 15 & 5 & 0 & 0 & 0 \\
\hline 1065 & 9 & 18 & 3 & 5 & 1 & 0 & 0 & 0 \\
\hline 1070 & 26 & 53 & 12 & 12 & 1 & 1 & 0 & 0 \\
\hline 1075 & 14 & 26 & 5 & 9 & 0 & 0 & 0 & 0 \\
\hline 1080 & 36 & 135 & 8 & 19 & 5 & 1 & 0 & 2 \\
\hline 1085 & 14 & 49 & 2 & 9 & 2 & 1 & 0 & 0 \\
\hline 1090 & 47 & 197 & 12 & 24 & 4 & 4 & 2 & 1 \\
\hline
\end{tabular}

Tabla 13. Evolución de abreviaturas por letra sobrepuesta en la documentación francesa (a partir de la Plataforma Telma: http://www.cn-telma.fr/)

\begin{tabular}{|l|c|c|c|c|c|c|c|c|c|}
\hline & 1050 & 1055 & 1060 & 1065 & 1070 & 1075 & 1080 & 1085 & 1090 \\
\hline qui & 8 & 8 & 29 & 7 & 20 & 3 & 54 & 14 & 63 \\
\hline pra & 1 & 7 & 9 & 0 & 6 & 3 & 11 & 5 & 25 \\
\hline quo & 1 & 0 & 14 & 3 & 6 & 4 & 19 & 5 & 33 \\
\hline uero & 2 & 1 & 4 & 2 & 0 & 7 & 12 & 6 & 16 \\
\hline pri & 4 & 0 & 6 & 3 & 5 & 5 & 16 & 6 & 17 \\
\hline cri & 1 & 0 & 0 & 0 & 0 & 0 & 2 & 1 & 0 \\
\hline qua & 1 & 0 & 9 & 3 & 1 & 1 & 3 & 6 & 14 \\
\hline mihi & 1 & 1 & 6 & 0 & 2 & 0 & 1 & 2 & 1 \\
\hline ergo & 0 & 0 & 2 & 0 & 0 & 1 & 3 & 0 & 1 \\
\hline igitur & 0 & 0 & 1 & 0 & 1 & 1 & 1 & 2 & 6 \\
\hline modo & 0 & 0 & 1 & 0 & 1 & 1 & 5 & 1 & 3 \\
\hline monacho & 0 & 0 & 0 & 0 & 11 & 0 & 0 & 1 & 16 \\
\hline tra & 0 & 0 & 0 & 0 & 0 & 0 & 4 & 0 & 1 \\
\hline nisi & 0 & 0 & 0 & 0 & 0 & 0 & 2 & 0 & 2 \\
\hline pro & 0 & 0 & 0 & 0 & 0 & 0 & 1 & 0 & 0 \\
\hline tri & 0 & 0 & 0 & 0 & 0 & 0 & 1 & 0 & 0 \\
\hline
\end{tabular}




\section{LÁMINAS}

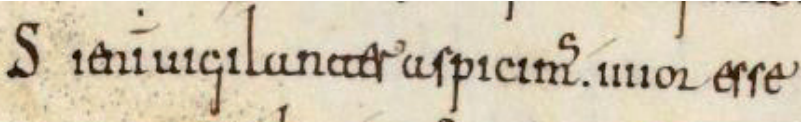 urratad Inuthim. quicutudithr facanb?}

Lám. 1. BL, Add. Ms.11695, f. 90r. Convivencia de signos abreviativos visigóticos (aspicimus) y carolinos (inuenimus, actibus).

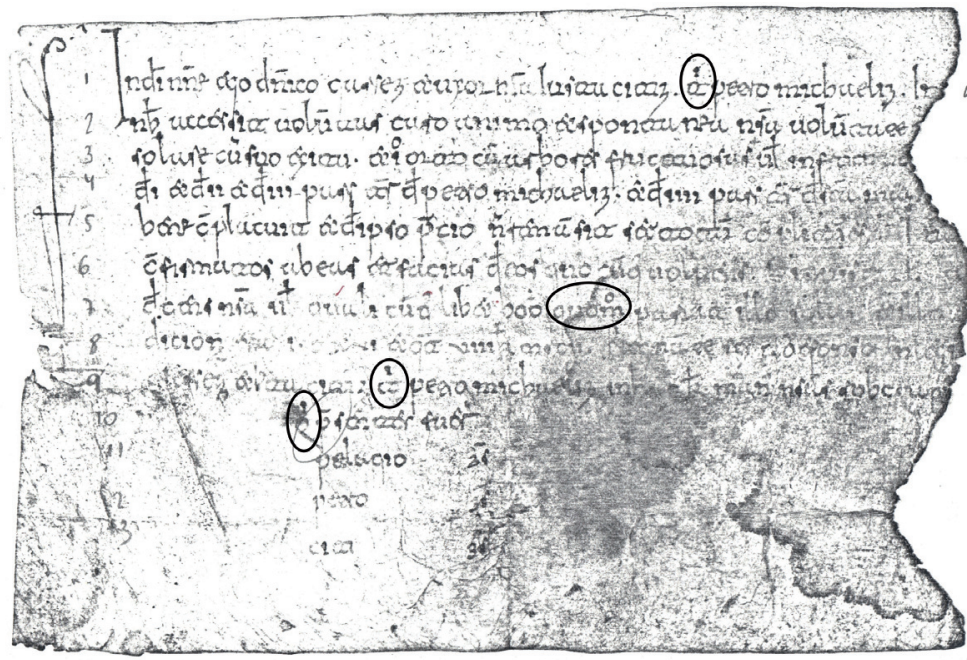

Lám. 2. ACL, n. ${ }^{\circ}$ 262. Primer testimonio del uso de abreviaturas por letra sobrepuesta en el ACL (1078): tibi (lín. 1 y 9), modo (lín. 7) y qui (lín. 10).
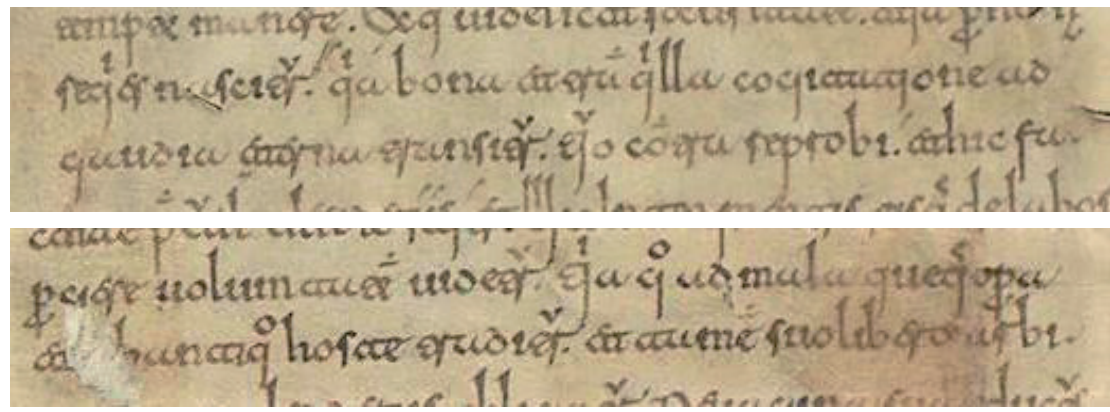

Lám. 3. AHN, 1. 1452/11, cols. c (supra) y d (infra).

Uso de letra sobrepuesta con valor abreviativo y sin él.

Atención a la aparición de $q^{v} o$ en la primera imagen y de hanti $q^{o}$ en la segunda. 


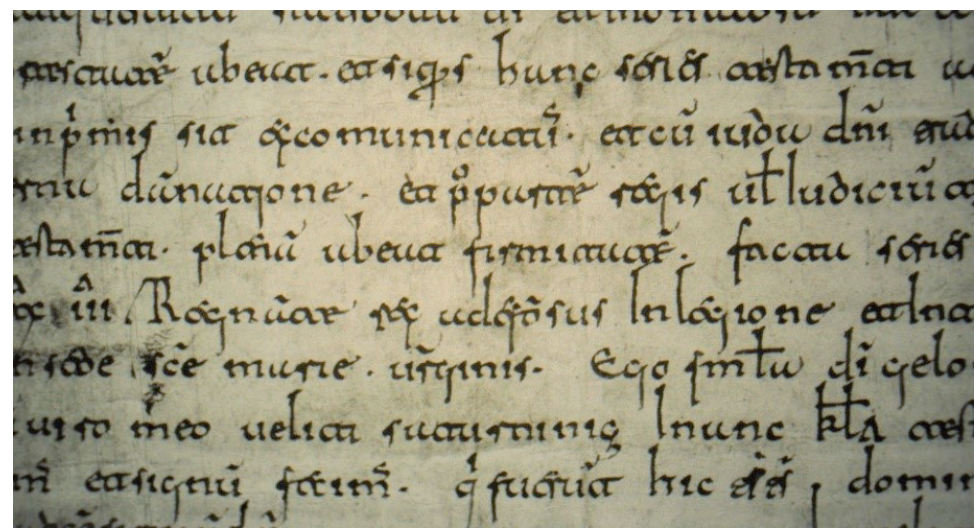

Lám. 4. AHN 960/9, lín. 16-23. Uso de abreviaturas por letra sobrepuesta en el Monasterio de Eslonza ( $p^{i} m i s, p^{o}, q^{i}$ ), junto al empleo de la grafía visigótica para qui (si quis).

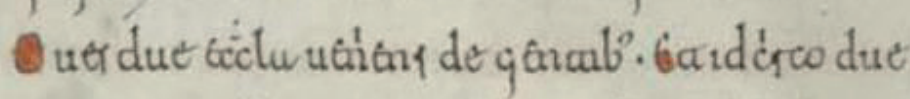

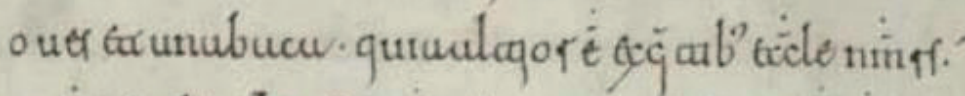

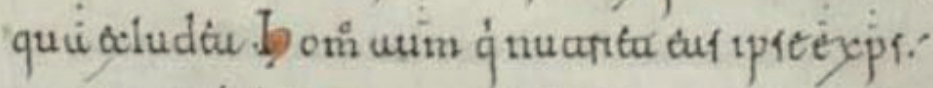

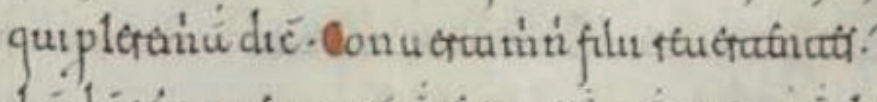

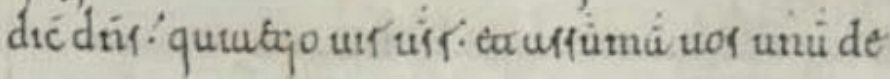

Lám. 5. BN, Mss/4339, f. 42r. Uso sistemático de vocales sobrepuestas sin valor abreviativo: uen ens, idcirco, hom ${ }^{o} \ldots$ (excepto $q^{i}$ en lín. 3).

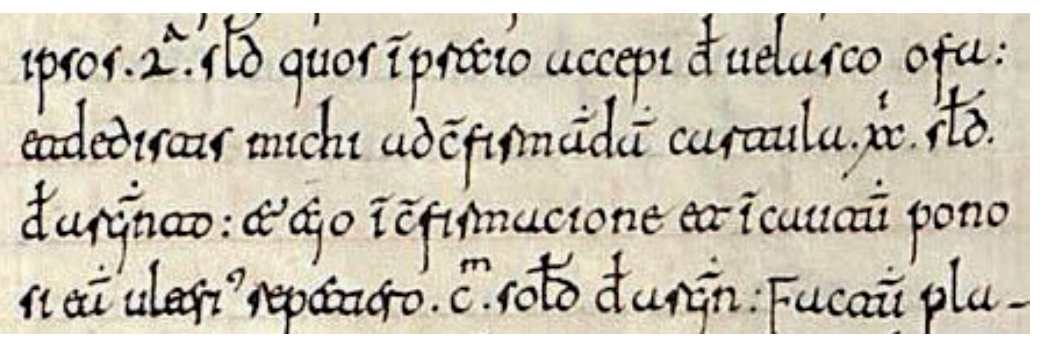

Lám. 6. AHN, 1. 989, f. 76v. Uso de la letra sobrepuesta en la abreviatura de numerales: $\mathrm{L}^{\mathrm{a}}$ (quinquaginta), $\mathrm{XX}^{\mathrm{i}}$ (viginti), $\mathrm{C}^{\mathrm{m}}$ (centum). 


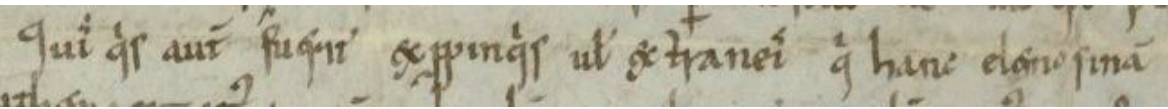

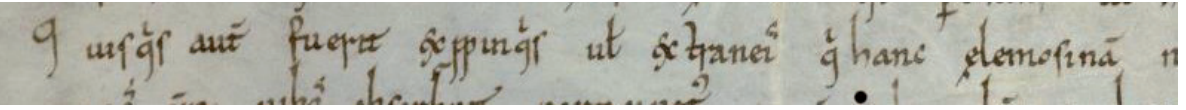

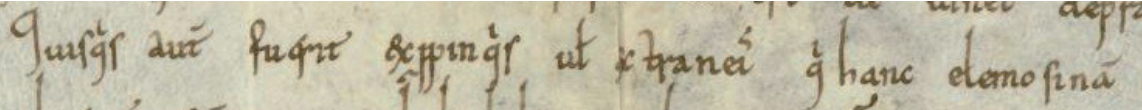

Lám. 7. ACV, n.os 10-57 (lín. 5), 12-1A (lín. 7) y 18-10 (lín. 6). La repetición de las mismas abreviaturas en los mismos lugares (quisqis, propinq's y $q^{i}$ ) podrían remitir a un formulario previo en el que ya aparecieran escritas de ese modo.

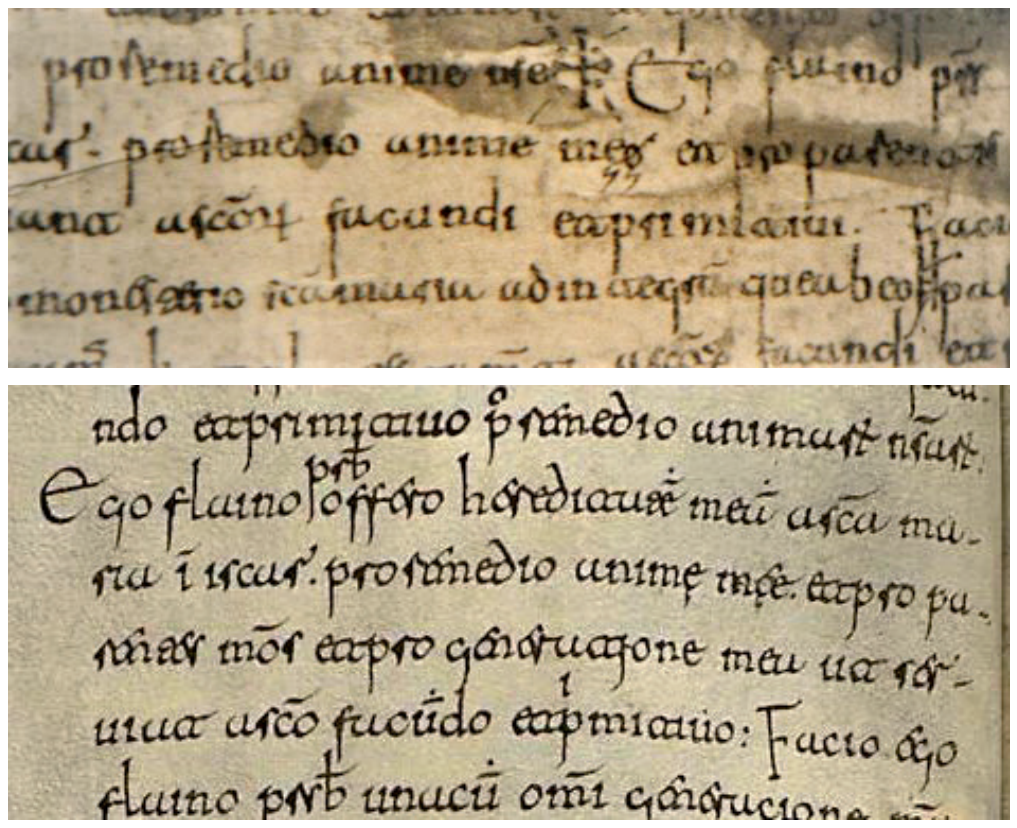

Lám. 8. AHN 886/18, lín. 27-30 (supra) y AHN, 1. 989, f. 141v (infra). Introducción por parte de Munio de abreviaturas por letra sobrepuesta en el Becerro cuyo original carecía de ellos: $p^{o}$ y $p^{i}$ mitiuo. 


\section{BIBLIOGRAFÍA CITADA}

Abad Barrasús, Juan (1985), El monasterio de Santa María de Puerto (Santoña). 863-1210, Santander, Institución Cultural de Cantabria.

Bell, Harold Idris (1953), Abbreviations in Documentary Papyri, en Studies Presented to David Moore Robinson on His Seventieth Birthday, vol. II, Saint Louis, Washington University, pp. 424-443.

Blanchard, Alain (1974), Sigles et abréviations dans les papyrus documentaires grecs: recherches de paléographie, Londres, University of London - Institute of Classical Studies.

Bozzolo, Carla; Coq, Dominique; Muzerelle, Denis; Ornato, Ezio (1990), Les abréviations dans les livres liturgiques $d u X V^{e}$ siècle: pratique et théorie, en Actas del VIII Coloquio del Comité Internacional de Paleografía Latina, Madrid, Joyas Bibliográficas, pp. 17-25.

Caligiani, Emilia (1993), Il sistema abbreviativo nei codici latini dal I al VII secolo, "Medioevo e Rinascimento" 7 (n.s. IV), pp. 253-290.

Calleja Puerta, Miguel (2011), La impaginatio en los documentos de Alfonso VII, expresión simbólica del poder real, en Impaginatio en las inscripciones medievales, León, CIHM, pp. 133-153.

Cappelli, Adriano (1912), Dizionario di abbreviature latini ed italiani, Milán, Hoepli.

Castro Correa, Ainoa (2012), La escritura visigótica en Galicia. I. Diócesis Lucense, Barcelona, Universitat Autònoma de Barcelona [en línea], http://ddd.uab.cat/record/127088, [consulta: 09/03/2020] (tesis doctoral).

Castro Correa, Ainoa (2016), Visigothic Script versus Caroline Minuscule: The Collision of Two Cultural Worlds in Twelfth-Century Galicia, "Mediaeval Studies" 78, pp. 203-242.

Castro Correa, Ainoa (2019), The regional study of Visigothic script: Visigothic script vs. Caroline minuscule in Galicia, en Change in Medieval and Renaissance scripts and manuscripts, Turnhout, Brepols, pp. 25-35.

Cencetti, Giorgio (1954), Lineamenti di storia della scrittura latina, Bolonia, Pàtron.

Chassant, Louis Alphonse (1876), Paléographie des chartes et des manuscrits du XI $I^{e}$ au XVII siècles, París, August Aubry.

Cohen-Mushlin, Aliza (1990), The Twelfth-Century Scriptorium at Frankenthal, en Medieval Book Production: Assessing the Evidence, Los Altos Hills, Anderson-Lovelace, pp. 85-101.

Collura, Paolo (1943), La precarolina e la carolina a Bobbio, Milán, Hoepli.

David, Pierre (1947), Études historiques sur la Galice et le Portugal du VI au XII ${ }^{e}$ siècle, Lisboa, Livraria Portugália - París, Les Belles Lettres. 
De Robertis, Teresa (1993), Questioni preliminari e generali, "Medioevo e Rinascimento" 7 (n.s. IV), pp. 161-193.

De Robertis, Teresa; Giovè, Nicoletta (2019), Come cambia la scrittura, en Change in Medieval and Renaissance scripts and manuscripts, Turnhout, Brepols, pp. 9-23.

Fernández Catón, José M. ${ }^{\text {a }}$ (1990), Colección documental del archivo de la Catedral de León (775-1230), vol. V (1109-1187), León, CEISI.

Fernández Flórez, José A. (1991), Colección diplomática del monasterio de Sahagún (857-1230), vol. IV (1110-1199), León, CEISI.

Fernández Flórez, José A. (2016), Escribir en los monasterios altomedievales del Occidente peninsular (siglos VIII-XII), en Lugares de escritura: el monasterio, Alicante, Universitat d'Alacant, pp. 17-67.

Fernández Flórez, José A.; Herrero de la Fuente, Marta (1995), Libertades de los copistas: el caso del Becerro Gótico de Sahagún, en Scribi e colofoni. Le sottoscrizioni di copista dalle origini all'avvento della stampa, Spoleto, Centro italiano di studi sull'Alto Medioevo, pp. 301-319.

Fernández Flórez, José A.; Herrero de la Fuente, Marta (1999), Colección documental del monasterio de Santa María de Otero de las Dueñas I (854-1108), León, CEISI.

Fernández Flórez, José A.; Herrero de la Fuente, Marta (2005), Colección documental del monasterio de Santa María de Otero de las Dueñas II (1109-1300) e índices, León, CEISI.

Fernández Flórez, José A.; Herrero de la Fuente, Marta (2009), Los documentos de Celanova y Sahagún en la época de san Rosendo (siglo X), en Rudesindus "San Rosendo. Su tiempo y su legado", Santiago de Compostela, Consellería de Innovación e Industria, pp. 73-99.

Francia Lorenzo, Santiago (coord.) (1987), Archivo Capitular de Palencia. Catálogo I, $2^{a}$ parte, "Publicaciones de la Institución Tello Téllez de Meneses" 55, pp. 1-581.

Gambra, Andrés (1997), Alfonso VI: cancillería, curia e imperio. I. Estudio, León, CEISI.

García Turza, Claudio; García Turza, Javier (1997), Fuentes españolas altomedievales, La Rioja, Real Academia de la Historia - Fundación Caja Rioja.

Giovè Marchioli, Nicoletta (1991), Per una storia delle abbreviature latine. Una prima ricognizione all'interno dei manoscritti giuridici, "Gazette du livre médiéval" 18, pp. 17-24.

Giovè Marchioli, Nicoletta (1993), Alle origini delle abbreviature latine, Mesina, Sicania. 
Giovè Marchioli, Nicoletta (2016), Ritorno al passato. Ancora sulle origini delle abbreviature latine, en Scriver veloce. Sistemi tachigrafici dell'antichità a Twitter, Florencia, Leo Olschki, pp. 41-62.

Gonzálvez Ruiz, Ramón (1997), Hombres y libros de Toledo, Madrid, Ramón Areces.

Grijuela Gil, Carmen (2016), Los documentos reales y monásticos del cartulario de Santa María del Puerto de Santoña, "Altamira: Revista del Centro de Estudios Montañeses" 87, pp. 7-28.

Herrero de la Fuente, Marta (1988a), Colección diplomática del monasterio de Sahagún (857-1230). II. 1000-1073, León, CEISI.

Herrero de la Fuente, Marta (1988b), Colección diplomática del monasterio de Sahagún (857-1230). III. 1074-1109, León, CEISI.

Herrero de la Fuente, Marta; Fernández Flórez, José A. (2012), Escritura y Diplomática en León en la época de Alfonso VI, en Alfonso VI y su legado. Actas del Congreso Internacional (Sahagún, 29 de octubre al 1 de noviembre de 2009), León, Diputación de León, pp. 89-114.

Honkapohja, Alpo (2013), Manuscript abbreviations in Latin and English: History, typologies and how to tackle them in encoding, "Studies in Variation, Contacts and Change in English" [en línea] 14, http:/ www.helsinki.fi/varieng/series/volumes/14/honkapohja/ [consulta: 09/03/2020].

Kwakkel, Erik (2018), Book Script, en The European Book in the Twelfth Century, Londres - New York, Cambridge University Press, pp. 25-42.

Lindsay, Wallace M. (1909), The Bobbio Scriptorium: Its Early Minuscule Abbreviations, "Zentralblatt für Bibliothekwesen" 25, pp. 293-306.

Lindsay, Wallace M. (1915), Notae Latinae. An Account of Abbreviation in Latin Mss. of the Early Minuscule Period (c. 700-850), Cambridge, Cambridge University Press (reimpreso en Hildesheim, Georg Olms, 1963, con un Suplemento de D. Bains).

McNamee, Kathleen (1981), Abbreviations in Greek Literary Papyri and Ostraca, Ann Arbor, The American Society of Papyrologists.

Millares Carlo, Agustín (1999), Corpus de códices visigóticos. I. Estudio, Las Palmas de Gran Canaria, UNED.

Miranda García, Fermín (2015), Autores carolingios en los códices hispanos (siglos IX-XI). Un ensayo de interpretación, "Studia historica. Historia medieval" 33, pp. 25-50.

Montenegro Valentín, Julia (2009), La alianza de Alfonso VI con Cluny y la abolición del rito mozárabe en los reinos de León y Castilla: una nueva valoración, "Iacobus: revista de estudios jacobeos y medievales" 25-26, pp. 47-62. 
Mundó Marcet, Anscari M. (1988), Importación, exportación y expoliaciones de códices en Cataluña (siglos VIII al XIII), en Coloquio sobre circulación de códices y escritos entre Europa y la Península, Santiago de Compostela, Universidad de Santiago, pp. 87-134.

Olmedilla Herrero, Carmen (1993), La ciencia paleográfica hispano-latina en el siglo XVI: edición y valoración de las Abreviaturas de Juan Vázquez Del Mármol, "Cuadernos de Filología Clásica" 4, pp. 191-232.

Ostolaza Elizondo, M. ${ }^{a}$ Isabel (1990), La transición de la escritura visigótica a la carolina en los monasterios del reino de León", en Actas del VIII Coloquio del Comité Internacional de Paleografía Latina, Madrid, Joyas Bibliográficas, pp. 149-162.

Parigino, Giuseppe (1993), Il sistema abbreviativo nelle carte dei secoli VIII e IX. Continuità, arrichimento, mutamento, "Medioevo e Rinascimento" 7 (n.s. IV), pp. 291-347.

Parkinson, Stephen R.; Emiliano, Antonio H. A. (2002), Encoding medieval abbreviations for computer analysis (from Latin-Portuguese and Portuguese non-literary sources), "Literary \& Linguistic Computing" 17/3, pp. 345-360.

Perea, Manuel; Acha, Joana; Carreiras, Manuel (2009), Eye movements when reading text messaging (txt msgng), "The Quarterly Journal of Experimental Psychology" 62, pp. 1560-1567.

Rand, Edward K. (1927), A Nest of Ancient Notes, "Speculum" 2, pp. 160-176. Reglero de la Fuente, Carlos M. (2008), Cluny en España: los prioratos de la provincia y sus redes sociales (1073-ca. 1270), León, CEISI.

Rodríguez de Lama, Ildefonso (1976), Colección diplomática medieval de La Rioja. Documentos (923-1168, tomo II), Logroño, Instituto de Estudios Riojanos - Diputación Provincial.

Romera Iruela, Luis (1988), El becerro gótico de Sahagún: esbozo de estudio codicográfico, "Anuario de Estudios Medievales" 18, pp. 23-42.

Rucquoi, Adeline (2010), Cluny, el camino francés y la reforma gregoriana, "Medievalismo" 20, pp. 97-122.

Ruiz Albi, Irene (2003), La Reina Doña Urraca (1109-1126): Cancillería y colección diplomática, León, CEISI.

Ruiz Asencio, José Manuel (1989) Colección documental del archivo de la Catedral de León (775-1230), vol. IV (1109-1187), León, CEISI.

Ruiz Asencio, José Manuel (2008), Cronología de la desaparición de la escritura visigótica en los documentos de León y Castilla, en Paleografía I. La escritura en España hasta 1250, Burgos, Universidad de Burgos, pp. 95-117.

Ruiz Asencio, José Manuel; Ruiz Albi, Irene (2007), Colección documental del monasterio de San Pedro de Eslonza I (912-1300), León, CEISI. 
Ruiz Asencio, José Manuel; Ruiz Albi, Irene; Herrero Jiménez, Mauricio (2010), Los becerros gótico y galicano de Valpuesta, Madrid, Real Academia Española - Burgos, Instituto Castellano y Leonés de la Lengua.

Ruiz García, Elisa (1994-1995), Una nueva aproximación al código alfabético, "Estudis castellonencs" 6, pp. 1223-1237.

Sáez, Emilio (1987), Colección documental del archivo de la Catedral de León (775-1230), vol. I, León, CEISI.

Sánchez Prieto, Ana Belén (2001), Las abreviaturas como indicadores de hábitos de lecto-escritura, "Norba" 15, pp. 159-168.

San Martín Payo, Jesús (1983), Catálogo del Archivo de la Catedral de Palencia, "Publicaciones de la Institución Tello Téllez de Meneses" 50, pp. 1-419.

Schiaparelli, Luigi (1926), Avviamento allo studio delle abbreviature latine nel Medioevo, Florencia, Leo S. Olschki.

Serna Serna, Sonia (2007), Munio y el Becerro Gótico de Sahagún: una muestra de su actividad como copista, en El monacato en los reinos de León y Castilla (siglos VII-XIII), León, Fundación Sánchez Albornoz, pp. 425-435.

Serna Serna, Sonia (2008), La desaparición de la escritura visigótica y la introducción de la escritura carolina en la Catedral de Burgos (10501150), en Paleografía I. La escritura en España hasta 1250, Burgos, Universidad de Burgos, pp. 201-212.

Serrano Sanz, Manuel (1918), Cartulario de la iglesia de Santa María de Puerto (Santoña) [I], "Boletín de la Real Academia de la Historia" 73, pp. 420-442.

Steffens, Franz (1913), Die Abkürzungen in den lateinischen Handschriften des 8. und 9. Jahrhunderts in St. Gallen, "Zentralblatt für Bibliothekwesen" 30, pp. 477-488.

Traube, Ludwig (1907), Nomina Sacra. Versuch einer Geschichte der christlichen Kürzung, Múnich, C. Beck.

Vézin, Jean (2003), El códice British Library Add. 30849 y la introducción de la carolina en España, en Silos. Un milenio, vol. II, Burgos, Universidad de Burgos, pp. 211-222.

Vivancos Gómez, Miguel C. (2012), Documentación en visigótica del monasterio de San Salvador de Oña, en Oña. Un milenio. Actas del Congreso Internacional sobre el monasterio de Oña (1011-2011), Burgos, Fundación Milenario San Salvador de Oña, pp. 52-81.

Fecha de recepción del artículo: abril 2019

Fecha de aceptación y versión final: junio 2020 